\author{
RESEARCH ARTICLE \\ 10.1029/2020JC016316 \\ Key Points: \\ - The coherent seasonal acceleration \\ of the barotropic flow significantly \\ contributes to the seasonal \\ variability in dense water outflow \\ - The seasonal flow strength is in \\ phase with the intensification of the \\ surface stress upstream of the dense \\ water formation region \\ - Our results suggest a \\ teleconnection to exist between \\ the eastern/northeastern Weddell \\ Sea winds and the barotropic flow
}

Supporting Information:

- Supporting Information S1

Correspondence to:

N. Le Paih,

nicolas.le.paih@awi.de

Citation:

Le Paih, N., Hattermann, T.,

Boebel, O., Kanzow, T., Lüpkes, C., Rohardt, G., et al. (2020). Coherent seasonal acceleration of the

Weddell Sea boundary current system driven by upstream winds. Journal of Geophysical Research: Oceans, 125, e2020JC016316. https://doi.org/10. 1029/2020JC016316

Received 15 APR 2020

Accepted 24 SEP 2020

Accepted article online 25 SEP 2020

\section{Coherent Seasonal Acceleration of the Weddell Sea Boundary Current System Driven by Upstream Winds}

\author{
Nicolas Le Paih ${ }^{1}$ (D) Tore Hattermann ${ }^{1,2}\left(\mathbb{D}\right.$, Olaf Boebel ${ }^{1}$, Torsten Kanzow ${ }^{1,3}$ (D) Christof Lüpkes $^{1}$, \\ Gerd Rohardt $^{1}(\mathbb{D})$, Volker Strass ${ }^{1}\left(\mathbb{D}\right.$, and Steven Herbette ${ }^{4}(\mathbb{D})$ \\ ${ }^{1}$ Alfred Wegener Institute, Helmholtz Centre for Polar and Marine Research, Bremerhaven, Germany, ${ }^{2}$ Norwegian \\ Polar Institute, Tromsø, Norway, ${ }^{3}$ Faculty of Physics/Electrical Engineering (FB 01) | Department of Geosciences (FB5), \\ University of Bremen, Bremen, Germany, ${ }^{4}$ Laboratoire d'Océanographie Physique et Spatiale (LOPS), IUEM, Univ. \\ Brest, CNRS, IRD, Ifremer, Brest, France
}

Abstract The Weddell Sea is of global importance in the formation of dense bottom waters associated with sea ice formation and ocean-ice sheet interaction occurring on the shelf areas. In this context, the Weddell Sea boundary current system (BCS) presents a major conduit for transporting relatively warm water to the Weddell Sea ice shelves and for exporting some modified form of Wedell Sea deep and bottom waters into the open ocean. This study investigates the downstream evolution of the structure and the seasonality of the BCS along the Weddell Sea continental slope, combining ocean data collected for the past two decades at three study locations. The interannual-mean geostrophic flow, which follows planetary potential vorticity contours, shifts from being surface intensified to bottom intensified along stream. The shift occurs due to the densification of water masses and the decreasing surface stress that occurs westward, toward the Antarctic Peninsula. A coherent along-slope seasonal acceleration of the barotropic flow exists, with maximum speed in austral autumn and minimum speed in austral summer. The barotropic flow significantly contributes to the seasonal variability in bottom velocity along the tip of the Antarctic Peninsula. Our analysis suggests that the winds on the eastern/northeastern side of the gyre determines the seasonal acceleration of the barotropic flow. In turn, they might control the export of Weddell Sea Bottom Water on seasonal time scales. The processes controlling the baroclinic seasonality of the flow need further investigation.

Plain Language Summary In the Weddell Sea, large amounts of seawater are cooled to become dense and sink, carrying signals of human-induced changes such as atmospheric carbon into the abyss of the ocean. Understanding the variability of the ocean currents at the Antarctic continental margin is critical because it controls both the export of the dense water formed in these areas and the access of warm water that may melt the Antarctic ice sheet. This study investigates the structure and the seasonality of the flow at the continental margin in the Atlantic sector of the Southern Ocean, using in situ observations upstream and downstream of the dense water formation regions. Following the bathymetry, ocean currents flow from East to West along the continental shelf edge. As water densifies along this path, the flow speed changes from being maximum at the ocean surface to be maximum at the bottom. The depth-averaged current varies with a synchronized seasonality along the continental shelf break, reaching a maximum in austral autumn. Our analysis suggests that the winds on the eastern/northeastern margin drives the seasonality of the depth-averaged flow along the shelf break, significantly contributing to changes in bottom velocity near the export region.

\section{Introduction}

The boundary current system (BCS) in the Weddell Sea is composed of the Antarctic Coastal Current (ACoC), the Antarctic Slope Current (ASC), and the dense water outflow confined along the Antarctic Peninsula eastern's shelf break (Thompson et al., 2018). The ACoC and the ASC follow the ice shelf edge and the continental slope, respectively. They transport a mix of water masses originating from the continental 

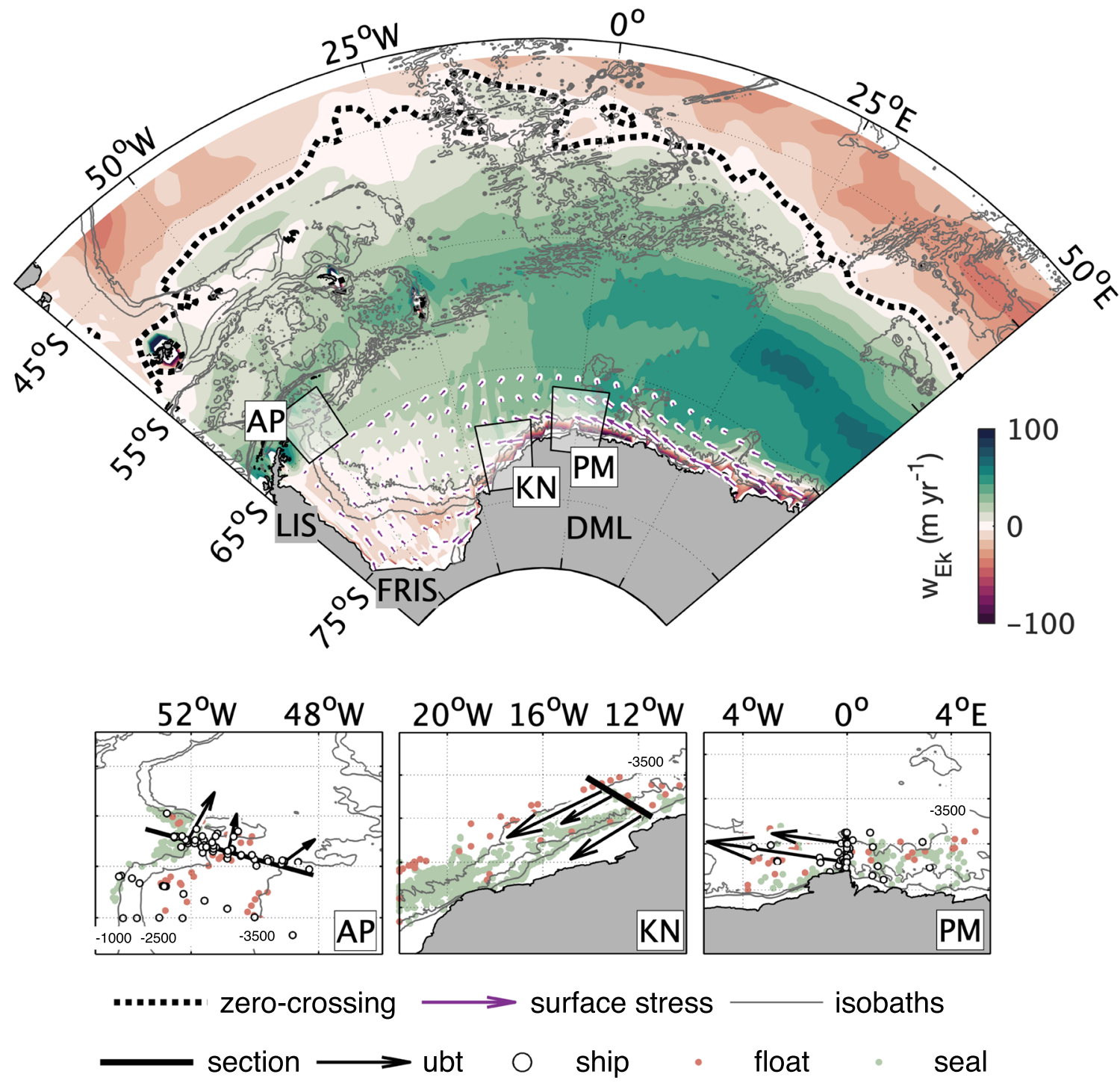

Figure 1. (top) Interannual-mean Ekman pumping, $\overline{w_{E k}}$ (colormap spaced by $10 \mathrm{~m} \mathrm{yr}^{-1}$ ). The black dotted line marks the northern zero crossing of $\overline{w_{E k}}$. The purple arrows represent the surface stress. Larsen C Ice Shelf (LIS), Filchner Ronne Ice Shelf (FRIS) and Dronning Maud Land (DML) are indicated. (bottom) Zoom of study areas, indicating the tip of the Antartic Peninsula (AP), Kapp Norvegia (KN), and the Prime Meridian (PM). Thick lines mark the nominal positions of the mapped sections, thin lines the positions of the 1,000;2,000; and 3,500 m isobaths. Black arrows represent the direction and strength of the mean barotropic flow (ubt) scaled to $5 \mathrm{~cm} \mathrm{~s}^{-1}$ (cf. legend). Positions of CTD, Argo float and seal-borne profiles are given by circles and red and green dots, respectively.

shelves and the open ocean. The continental shelf waters are the fresh waters formed on the narrow continental shelf offshore of the Dronning Maud Land (DML at $\left.0^{\circ} \mathrm{E}\right)$ and the dense shelf waters formed offshore the Filchner Ronne Ice Shelf (FRIS at $50^{\circ} \mathrm{W}$ ) and the Larsen Ice Shelf (LIS at $60^{\circ} \mathrm{W}$ ). The open ocean waters are mainly the Circumpolar Deep Water (CDW) emerging from the upwelling branch of the global overturning circulation. $\mathrm{CDW}$ enters the Weddell gyre around $30^{\circ} \mathrm{E}$ by the Southern Indian Ridge. The ridge deflects the Antarctic Circumpolar Current southward and generates a residual circulation, which supplies the Weddell Sea with warm and salty waters (Leach et al., 2011; Park et al., 2001; Ryan et al., 2016). Once embedded within the boundary currents, the shelf and open ocean waters are transported westward, undergo mixing, and gradually transform into modified Warm Deep Water (mWDW), Weddell Sea Deep Water (WSDW) and Weddell Sea Bottom Water (WSBW) (Orsi et al., 1999). Upstream of the dense water formation regions, the BCS can be approximated as a two-layer system where the pycnocline slopes downward toward the coast (Heywood et al., 1998; Núñez Riboni \& Fahrbach, 2009). Downstream, the pycnocline forms a v-shaped front across the continental slope and the BCS shifts from a two-layer to a three-layer system due to the presence 
of a dense plume of WSBW at the bottom (Gill, 1973; Thompson \& Heywood, 2008). This along-slope change in density regimes, that is, shifting from fresh shelf to a dense shelf (Thompson et al., 2018), determines the structure of the baroclinic flow and the strength of the dense water outflow at the tip of the Antarctic Peninsula (AP). In turn, this outflow contributes to feed the lower branch of the global overturning circulation (Jullion et al., 2014).

The BCS is believed to control both the inflow of mWDW onto the southern Weddell Sea continental shelf and the export of dense water on seasonal time scales (Årthun et al., 2012; Meijers et al., 2016; Ryan et al., 2017). Earlier studies have investigated the seasonality of the BCS upstream and downstream of the dense water formation regions of the Weddell Sea, independently of each other (see regions in Figure 1). Two separate analyses of moored current meters at the Prime Meridian (PM) (Núñez Riboni \& Fahrbach, 2009) and Kapp Norvegia (KN) (Graham et al., 2013) have revealed a maximum (minimum) depth-averaged flow strength in autumn (early summer). At both sites, the variability was associated with the seasonal cycle in local winds and modulated both by the sea ice concentration and the thermohaline properties of surface waters. The along-slope surface stress, which is either applied by the wind or the sea-ice onto the top ocean layer, controls the onshore convergence of water masses via Ekman transport. The variability in surface water properties controls the stratification, that is, the density difference between surface and deep waters. The combination of both processes determines the cross-slope surface elevation and the density gradient across the continental slope, setting the strength of the barotropic current and the baroclinic structure of the flow (Hattermann, 2018; Nøst et al., 2011). The downstream advection of density anomalies also contributes to set the baroclinic structure of the flow (Graham et al., 2013). Fahrbach et al. (2001) and Gordon et al. (2010) separately focused on the seasonal cycle of dense water outflow at AP, using 1-year-long time series. A synthesis of both studies reveals a maximum (minimum) transport in early winter (summer) associated with a cold pulse of dense waters in autumn and a warm one in spring. Gordon et al. (2010) argued that these seasonal fluctuations can be related to the summer release of shelf waters formed on the western margin due to the weakening of the along-slope wind. However, this mechanism cannot be confirmed on seasonal time scales (Darelius et al., 2014). Daae et al. (2018) highlighted the correlation between the variability in surface stress and the variability in Filchner Trough overflow on shorter time scales. They explain that the outflow of dense water in front of FRIS is partly controlled by the circulation associated with the along-slope winds.

A synoptic view of the flow structure, its evolution along the continental slope, and connection to the large-scale forcing is still lacking. In this study we combine, in a novel approach, historical observations from three mooring sites dispatched along the continental slope, with ship-based Argo float and seal-borne CTD profiles. The aim is to provide an overview and consistent description of the seasonal cycle of the BCS, upstream and downstream of the dense water formation region, that is, at $\mathrm{PM} / \mathrm{KN}$ and at $\mathrm{AP}$, respectively (Figure 1). Ship-based Argo float and seal-borne CTD profiles are used to map cross-slope sections at the three study sites and compare the interannual-mean changes in ocean properties between the study locations. Multiyear mooring-based time series are combined to consistently explore the seasonality at the three study sites, across the continental slope. Finally, changes in the ocean are related to the spatial and temporal variability in surface stress. Section 2 describes the methods, section 3 presents interannual averages and seasonal variations of ocean velocity, hydrographic properties, and surface stress.

\section{Methods}

\subsection{Climatology Sections of Hydrographic Properties}

The ship-based data available for the cross-slope transects of PM, KN, and AP is combined with all available ARGO and seal-borne CTD profiles located within the vicinity of each section (Argo, 2017; Driemel et al., 2017; Treasure et al., 2017). Optimal interpolation (OI) is applied to temperature and salinity of the collected data sets in the planetary potential porticity $(P P V=f / h)$ versus depth $(Z)$ space (the data points used for the OI are given in Figure 2). This technique is normally used to produce accurate maps of temperature and salinity from sparse, irregularly sampled data of different accuracy (Böhme \& Send, 2005; Gandin, 1965; Reeve et al., 2016). Applying the method in the $P P V-Z$ space ensures an optimal remapping of the data, in the cross-slope direction, for a particular transect. CTD profiles are weighted equally as a function of time to include enough data. Inclusion of all available profiles results in a summer bias of the interpolation when data are sparse in winter. This bias is discussed in section 3.1.1. We assume the observed water mass to be advected from the transect to its observed position (or vice versa) by a geostrophically balanced flow that 

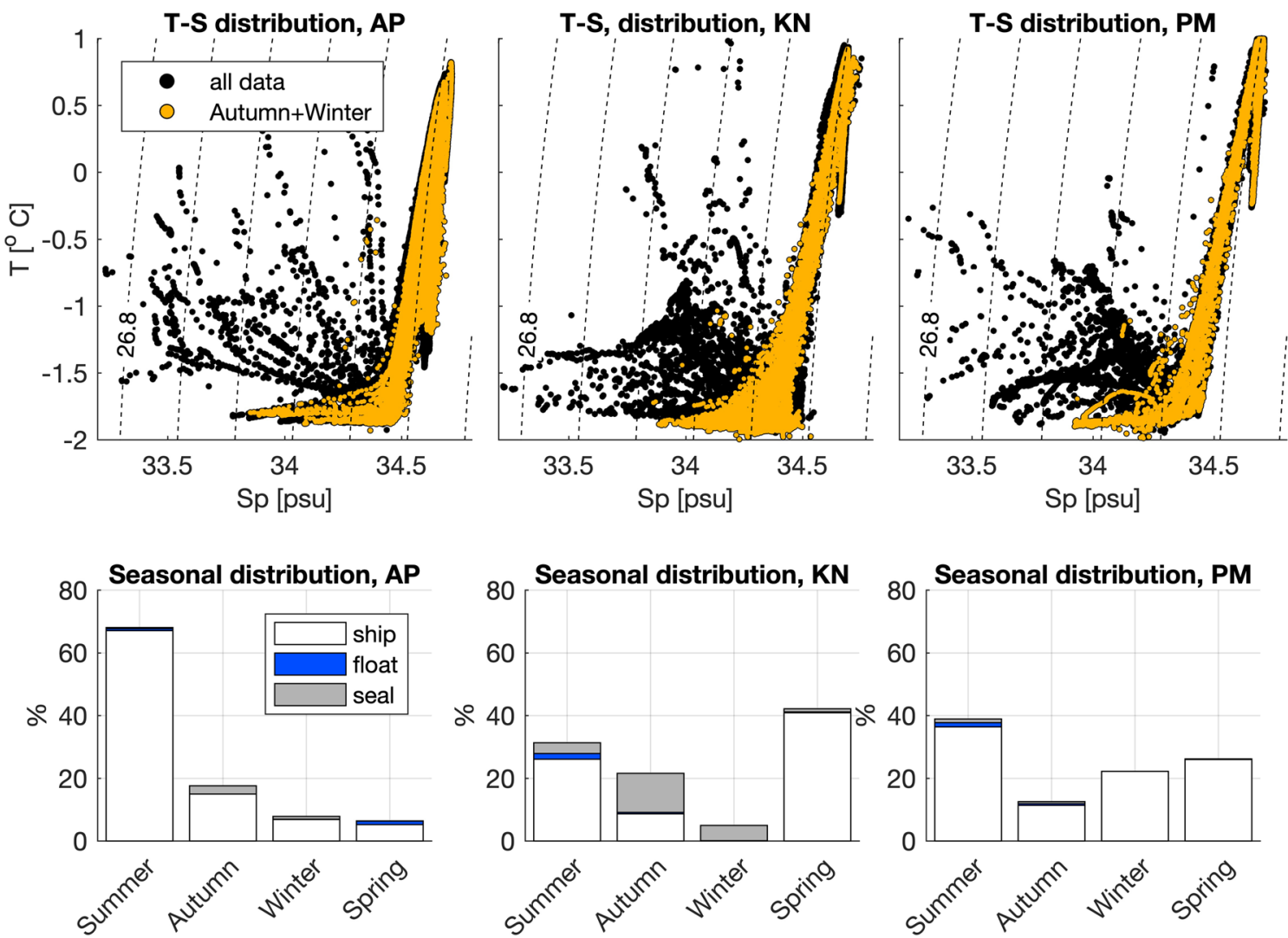

Figure 2. T-S diagram of the data fed into the optimal interpolation (OI) at (right column) PM, (middle column) KN, and (left column) AP. The seasonal distribution of the data observed above $1,000 \mathrm{~m}$ depth and used for the OI is indicated below the T-S diagrams.

follows ispoleths of PPV. Thus, the data are weighted equally along the PPV contour. In the Weddell Sea, along-slope diabatic changes can only be neglected locally (Reeve et al., 2016). Assuming a typical barotropic flow of $10 \mathrm{~cm} \mathrm{~s}^{-1}$ and diabatic changes occurring at the seasonal time scale ( $\tau=80$ days), we considered all data within $350 \mathrm{~km}$ of each transect to be valid. Temperature and salinity sections are first estimated in PPV-depth space at each location. Since the vertical resolution of the ship-based profiles is too high to assimilate all the data at once, the data set is split into subdata sets corresponding to subdomains (Text S1 in the supporting information). Considering a vertically stratified ocean, the subdata sets are selected within constant depth-layers at PM and KN and terrain-following depth layers at the tip of the AP. While the former coordinates provided better results in the vicinity of the thermocline depth, the latter proved to be more performant in mapping the dense bottom layer at AP. Finally, PPV-depth estimates are remapped on to cross-slope distance- $Z$ space to calculate the geostrophic velocities. These velocities are defined as the depth integral of the thermal wind balance equation. The reference level is defined by the lowest speed recorded by the current meters across the slope, that is, at the bottom at PM/KN and at $200 \mathrm{~m}$ depth at AP. Details on the $\mathrm{OI}$ are given in Text $\mathrm{S} 1$ in the supporting information.

\subsection{Seasonal Variations in Temperature and Speed}

Moored current meter data collected between 1989 and 2017 are compiled at the three different study locations to compare the seasonal variations of temperature and velocity upstream and downstream of the dense water formation regions (data coverage given in Figure 3). At each study location, data from instruments located at different depths in the water column have been compiled separately for each moorings that were deployed across the BCS, over the 1,000; 2,000-2,500; and 3,000/3,500 m isobaths. Records collected at the same position and within the same depth range are compiled to obtain multiyear time series divided into uniformly sampled interval periods. Three-hourly records are resampled at 2-hourly intervals, gaps associated with the turnaround of the moorings are interpolated and, a fifth-order low-pass Butterworth filter is applied on the interval periods to filter out frequencies higher than $1 / 30$ days. Note that the data recorded 

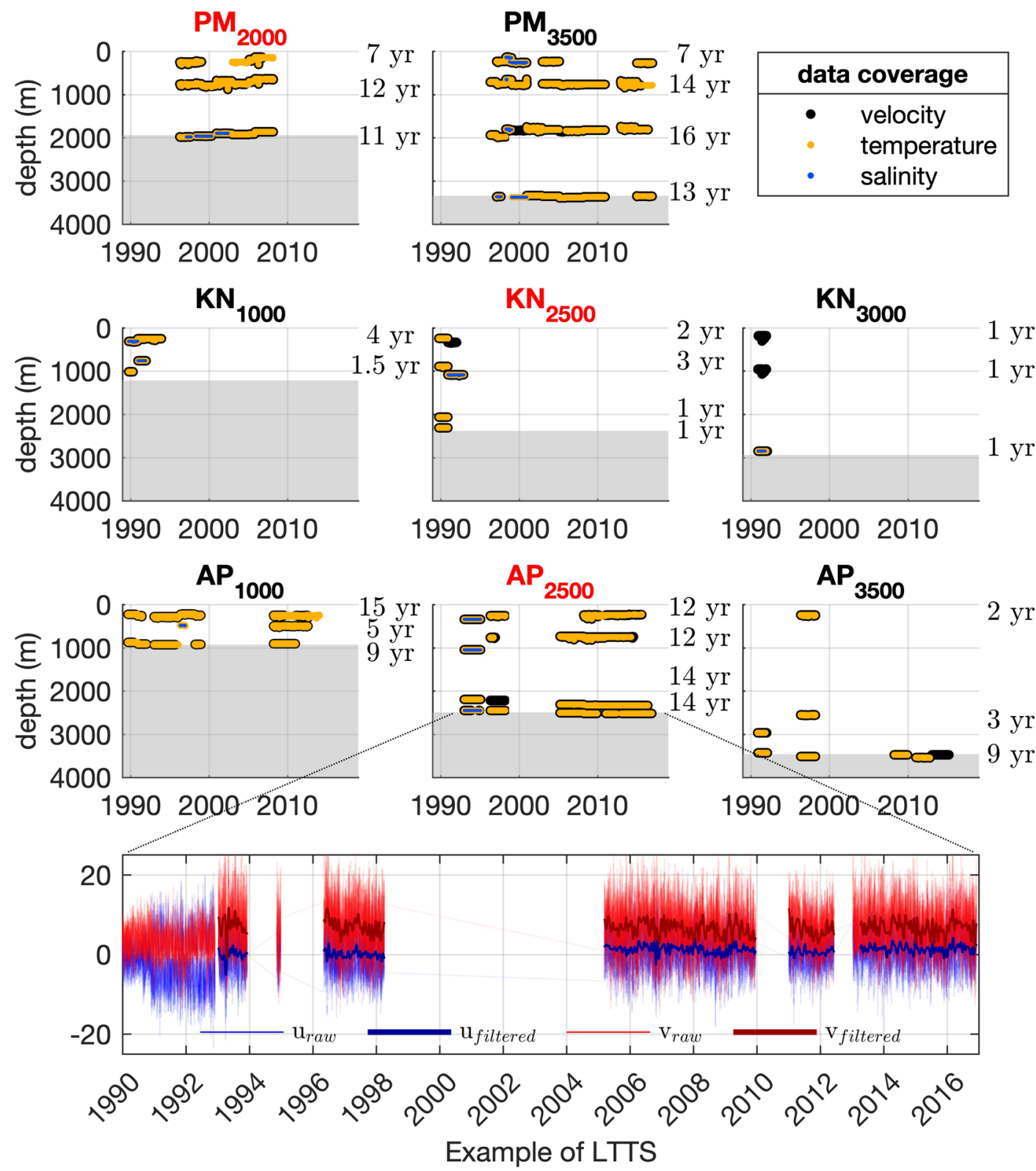

Figure 3. Moored data available for seasonal analysis. Velocity, temperature, and salinity data points are plotted on top of each other to highlight the overlapping data. The length of the velocity record is given in years (yr) at each level. The moorings labeled red are used to estimate the barotropic seasonality along the $2,000-2,500 \mathrm{~m}$ isobaths. The bottom panel shows an example of multiyear time series of zonal and meridional velocity constructed from the moored current meters at the bottom of $\mathrm{AP}_{2500}$.

between 1990 and 1994 at AP are discarded because the mooring were then located at a slightly different position than for the rest of the record, leading to differences in velocity regimes (Figure 3, bottom panel). The multiyear time series are averaged monthly for all available years to deduce the seasonal cycle of temperature and velocity at each depth. The standard error associated with the multiyear average of monthly means is defined for each month as

$$
\sigma_{e r r}(m)=\frac{\sigma(m)}{\sqrt{N}}
$$

where, $m$ is the month. $\sigma$ is the monthly standard deviation of the multiyear averages and $N$ is the effective number of degrees of freedom. Since the decorrelation time scales $\left(d_{\tau}\right)$ range between 20 days and 6 months, $N$ is also the number of years used to calculate the seasonal cycles because no two (or more) independent 
values exist within a given month of any year. Note that salinity measurements are too sparse to perform a seasonal analysis. Finally, a piecewise cubic hermite interpolating polynomial is used to infer a continuous vertical velocity profile between the instrument depths. Multiyear averages of monthly velocity profiles are depth averaged to estimate the seasonal cycle of barotropic velocity. The seasonal cycle of barotropic velocity is subtracted from the multiyear average of monthly velocities at the surface and at the bottom to estimate the remaining baroclinic seasonal cycle. Hereinafter, $u$ refers to the velocity projected onto the interannual-mean barotropic direction while the velocity normal to this direction is not considered in this study. The error associated with the vertical average is defined in Text S2.

\subsection{Seasonal Variations in Surface Stress}

Seasonal maps of surface stress are constructed to estimate the momentum transfer into the ocean. Following Dotto et al. (2018), the surface stress is weighted as a function of the wind velocity at $10 \mathrm{~m}$ above sea level $\left(u_{\text {air }}\right)$, the sea ice concentration $(\alpha)$ and the sea ice velocity $\left(u_{i c e}\right)$ :

$$
\vec{\tau}_{\text {wicv }}=\alpha \vec{\tau}_{\text {ice-ocean }}+(1-\alpha) \vec{\tau}_{\text {air-ocean }}
$$

where

$$
\begin{aligned}
& \vec{\tau}_{\text {ice-ocean }}=\rho_{o} C_{i o}\left|\vec{u}_{i c e}\right| \vec{u}_{i c e} \\
& \vec{\tau}_{\text {air-ocean }}=\rho_{a} C_{a o}\left|\vec{u}_{\text {air }}\right| \vec{u}_{\text {air }}
\end{aligned}
$$

$\rho_{a}$ and $\rho_{o}$ are the air and the ocean density set to 1.25 and $1,027 \mathrm{~kg} \mathrm{~m}^{-3}$, respectively. $C_{a o}$ and $C_{i o}$ are the air ocean and ice ocean drag coefficient set to $1.25 \times 10^{-3}$ and $5.5 \times 10^{-3}$, respectively. This formulation assumes an ocean at rest, neglecting the stress applied by the surface currents onto the ice floes, which might create a bias in the estimation of the surface stress in the vicinity of the BCS (Stewart et al., 2019). To check the robustness of our results and relate them to previous studies, results obtained using the formulation of Dotto et al. (2018) are compared with results from three additional methods of calculating surface stresses: one assuming a constant drag coefficient set to $1.5 \times 10^{-3}\left(\tau_{w}\right)$ (Armitage et al., 2018), the second accounting for the sea ice concentration and distinguishing between skin drag over smooth floes and form drag over floe edges $\left(\tau_{\text {wic }}\right)$ (Lüpkes \& Gryanik, 2015; Lüpkes et al., 2012); and the last using surface stress output from a locally high-resolution configuration of the FESOM model $\left(\tau_{\text {model }}\right)$ (Timmermann et al., 2012). Multiyear time series of surface stresses were constructed using daily outputs of wind velocity from ERA-Interim (Dee et al., 2011) and daily satellite observations of sea ice concentration and velocity (Cavalieri et al., 1996; Tschudi \& Maslanik, 2019). These time series were filtered with a 30-day low-pass filter, and averaged monthly and interannualy between 1989 and 2016 to produce seasonal maps of surface stress. The standard error associated with the calculation of the multiyear average of monthly means is given by Equation 1. Zonal and meridional components are projected onto the along-shore direction and averaged across the continental slope to estimate the along-slope surface stress, indicating the coastal convergence of water masses via Ekman transport. Finally, the Ekman pumping $\left(w_{E k}\right)$ is used to locate the upwelling and downwelling areas

$$
w_{E k}=\vec{\nabla} \times\left(\frac{\vec{\tau}}{\rho_{o} f}\right)
$$

where $f$ is the Coriolis force and $\vec{\tau}$ is the surface stress, which differs depending on the method of calculation.

\subsection{Analysis of Forcing Variability}

An empirical orthogonal function analysis (EOF) was performed on multiyear average of monthly maps of sea-level anomalies (SLA) (Armitage et al., 2018) and surface stress to assess the dominant mode of seasonal variability at the surface. Because data were not available before 2011, the monthly SLA were averaged between 2011 and 2016 instead of 1987 and 2016 for the surface stress (section 2.3). The modal decomposition is defined such that the modes are statistically independent from each other (Emery \& Thomson, 2001),

$$
\operatorname{Map}(x, y, t)=P C_{1}(t) \times m_{1}(x, y)+P C_{2}(t) \times m_{2}(x, y)+\epsilon(x, y, t)
$$

where $P C$ and $m$ represent the monthly varying principal component and the spatial distribution of the two first modes, respectively. $\epsilon$ represents the variability explained by higher modes. The domain used to perform the EOF extends zonally from $65^{\circ} \mathrm{W}$ to $60^{\circ} \mathrm{E}$ and meridionally from the edge of the ice shelf to the northern zero crossing of the Ekman pumping averaged over the years $\left(\overline{w_{E k}}\right.$, Figure 1$)$. 


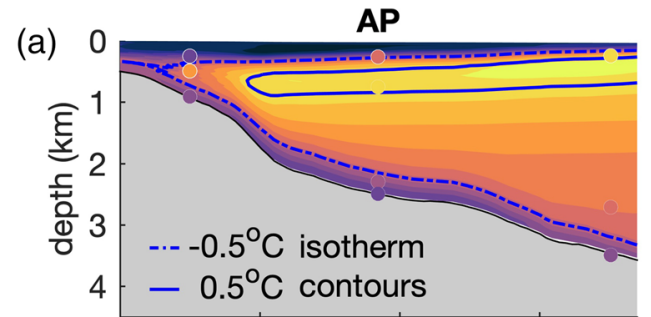

(b)

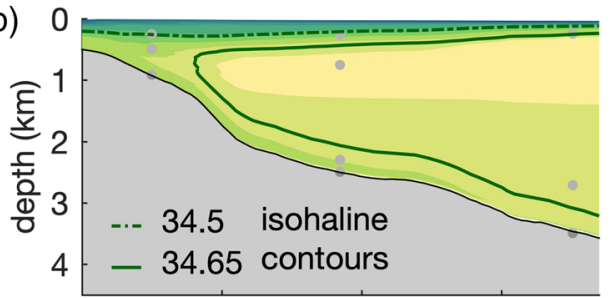

(c)

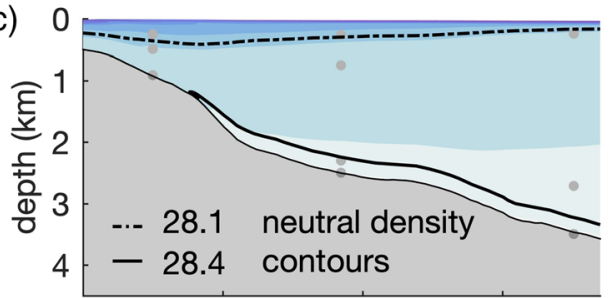

(d)

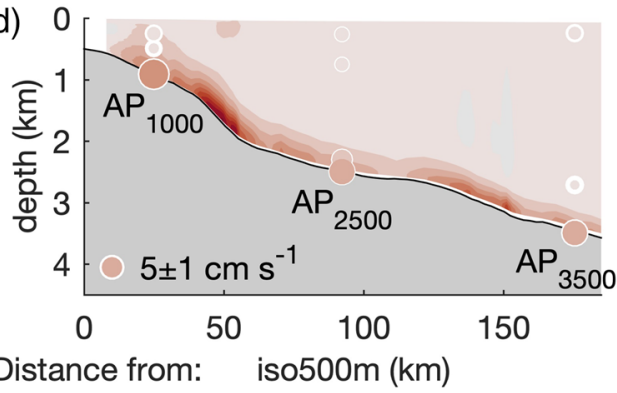

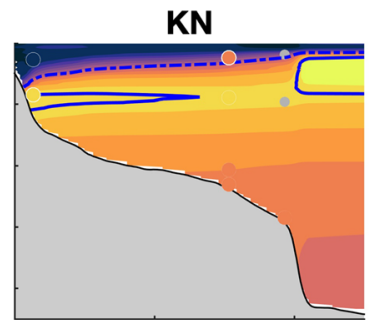
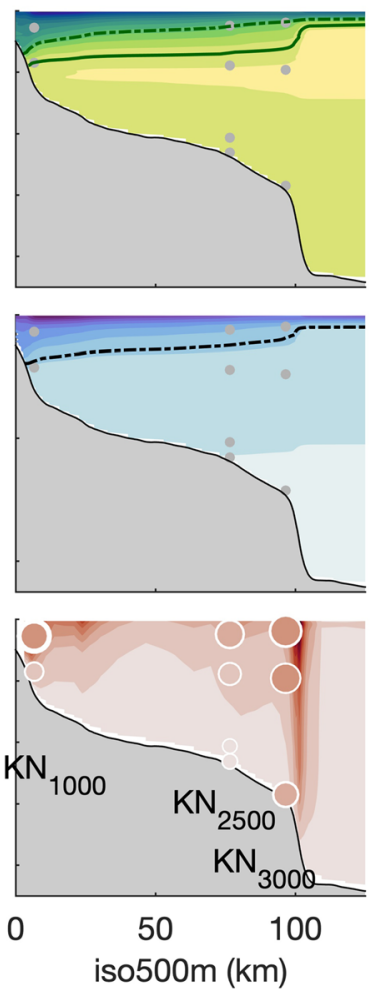

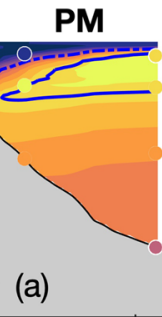

$\mathrm{T}\left[{ }^{\circ} \mathrm{C}\right]$
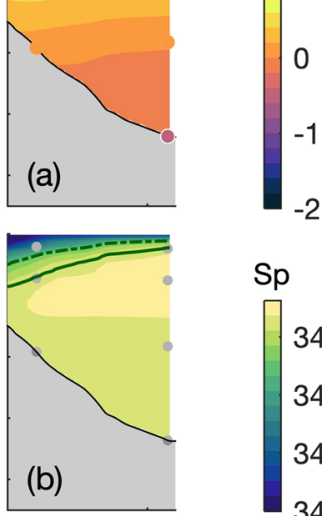

$\mathrm{Sp}$ 34.6

34.2

34

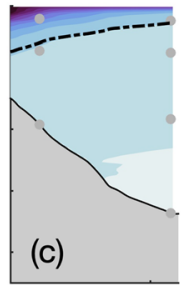

$\rho_{\mathrm{p}}\left[\mathrm{kg} \mathrm{m}^{-3}\right]$
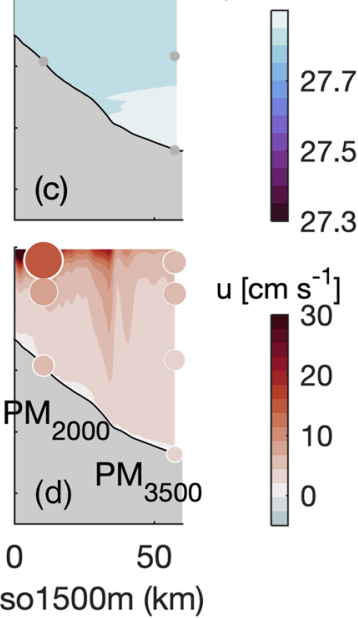

Figure 4. Climatologic sections of mean (a) in situ temperature, (b) practical salinity, (c) potential density, and (d) along-slope baroclinic velocities derived from the thermal-wind relation at AP, KN, and PM. The thermal-wind-derived velocities are referenced at the bottom at PM and $\mathrm{KN}$ and at $200 \mathrm{~m}$ depth at AP. The sections are biased toward summer at the AP (Figure 2). Points with an interpolation error larger than $0.1^{\circ} \mathrm{C}$ and 0.02 practical salinity were discarded. The mean properties measured by the current meters are plotted on top of the sections. Gray dots: positions of the moored current meters. Colored circles: interannual-mean temperature and along-slope velocity measured by the moored current meters. The area of the latter are proportional to the amplitude of the velocity.

\section{Results}

\subsection{Along-Slope Changes of BCS Properties}

\subsubsection{Interannual-Mean State}

Our reconstructed cross-slope transects show an along-slope densification of the water masses that is consistent with previous findings (Fahrbach et al., 1994; Gill, 1973; Orsi et al., 1999). The stratification shifts from a two-layer system upstream of the dense water formation regions to a three-layer system downstream (Figure 4). To delimit the layer interfaces, we here choose the 28.1 and 28.4 neutral density contours. At PM and $\mathrm{KN}$, a subsurface density front, roughly located between 200 and $800 \mathrm{~m}$ over the continental slope, separates cold and fresh waters onshore from the warm and salty waters offshore (Figures $4 \mathrm{a}$ and $4 \mathrm{~b}$ ). At AP, waters located onshore (offshore) of the continental slope are warmer and saltier (colder and fresher) than at $\mathrm{PM} / \mathrm{KN}$, which results in a weaker density front. This can be observed from the shape of the 28.1 neutral density contour, which ascends from an averaged depth (offshore depth) of $450(200 \mathrm{~m})$ at PM and KN to an averaged depth (offshore depth) of $300 \mathrm{~m}(150 \mathrm{~m})$ at AP. A third layer of dense water, not present at PM and $\mathrm{KN}$, also appears in the vicinity of the seafloor at AP (Figure 4c, neutral density contour 28.4). Accordingly, the cross-slope density gradient is reversed in the vicinity of the seafloor at AP. 


\section{(a) temperature at $\mathbf{2 0 0} \mathrm{m}$ depth}
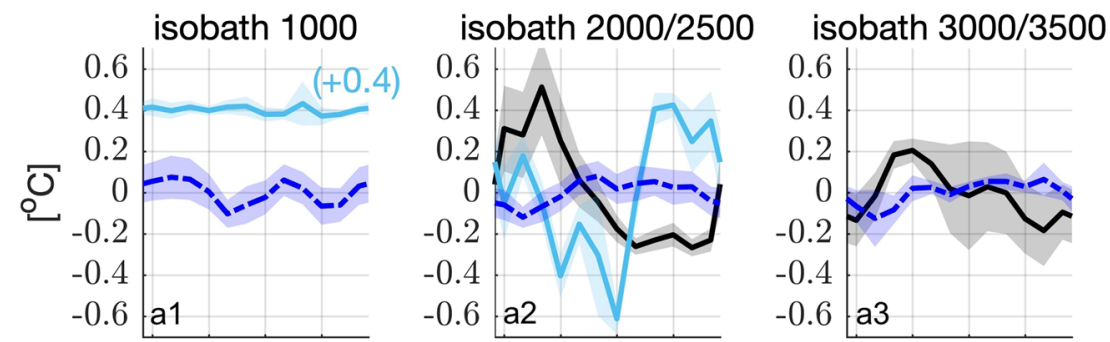

(b) temperature at $700-1000 \mathrm{~m}$ depth
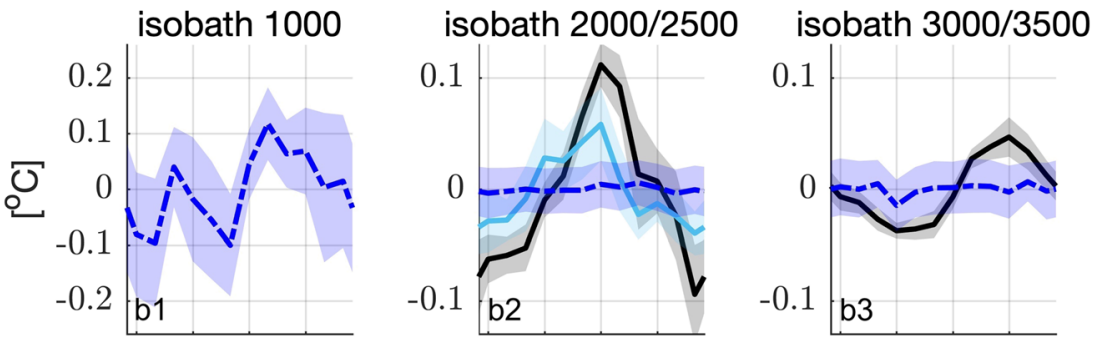

\section{(c) temperature at the bottom}
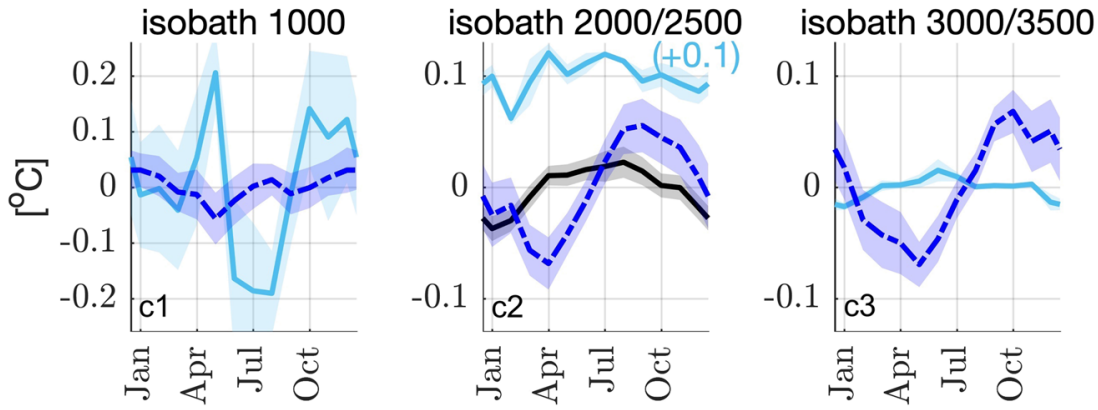

$\longrightarrow \mathrm{PM}=\mathrm{KN}$-ேー-ーAP

Figure 5. Seasonal cycle of temperatures estimated at the three study sites at the 1,000;2,000/2,500; and 3,000/3,500 m isobaths at (a) $200 \mathrm{~m}$ depth, (b) middepth, and (c) the bottom. The shaded areas represent the standard error. Note the difference in scale between the plots. Some temperature cycles are shifted along the $y$ axis to avoid overlap with the other cycles, with cyan colored numbers indicating the respective shift in ${ }^{\circ} \mathrm{C}$.

In agreement with the thermal wind balance, these changes in hydrographic properties are accompanied by changes in the vertical structure of the flow (Figure 4d). The along-slope weakening in the subsurface density gradient and its reversal at the bottom lead to a shift in the baroclinic structure of the flow from being surface to bottom intensified. At PM and KN, the multiyear-mean speeds recorded by the current meters ranges from 5 to $15 \mathrm{~cm} \mathrm{~s}^{-1}$ at $200 \mathrm{~m}$ depth, across the continental slope, and from 2 to $6 \mathrm{~cm} \mathrm{~s}^{-1}$ near the bottom. At AP, the average current velocity is as low as $2 \mathrm{~cm} \mathrm{~s}^{-1}$ throughout almost the entire water column. The exception occurs in the $300 \mathrm{~m}$ thick bottom layer of WSBW where the flow speed ranges between 6.5 to $9 \mathrm{~cm} \mathrm{~s}^{-1}$. In addition to the changes in baroclinic shear, the magnitude of the flow speed decreases between $\mathrm{KN}$ and AP $\left(u_{\max }>30 \mathrm{~cm} \mathrm{~s}^{-1}\right.$ at KN and $u_{\max }<20 \mathrm{~cm} \mathrm{~s}^{-1}$ at AP, Figure $4 \mathrm{~d}$ ). The decrease in depth-averaged flow speed is at least partly explained by mass conservation of the geostrophic current, which follows the diverging topography. Indeed, the distance between the isobaths at AP is twice as large as that at KN: Cisewski et al. (2011) and Heywood et al. (1998) respectively describe a boundary current of 75-100 km width at the PM and KN, while Thompson and Heywood (2008) relate a width of $200 \mathrm{~km}$ at AP. 
These observations are valid, regardless of the summer bias of the data used to construct the interannualmean sections (Figure 2). For example, the OI does not capture the warmer temperature observed by the current meters between July and December at $200 \mathrm{~m}$ depth at $\mathrm{KN}_{2500}$ and $\mathrm{AP}_{2500}$, and at $400 \mathrm{~m}$ depth at $\mathrm{AP}_{1000}$ (Figures 4a and 5). However, the temperature is well reproduced elsewhere and the thermal-wind-derived baroclinic velocities are consistent with the current meter measurements (Figure 4d).

\subsubsection{Seasonal Variability}

The previous subsection emphasized some along-slope change of the hydrological properties of the water masses carried by the BCS. This subsection focuses on the seasonal variability of the temperature at the three different mooring sites. Nevertheless, at KN, the seasonal cycle of temperature could not be retrieved because the time series were too short. On the shallower edge of the continental slope, above the $1,000 \mathrm{~m}$ isobath, our data set shows no seasonality at any of the three mooring sites, except for the bottom of AP (Figure 5, left panels). This highlights a larger sensitivity to subseasonal processes such as dense water runoff and/or frontal meanders. Above the middle and outer edge of the continental slope (i.e., above the 2,000/2,500 and 3,000/3,500 isobaths, respectively), observations show a gradual shift toward bottom amplified seasonal variations of temperature along the slope (Figures 5, middle panels and 5, right panels), which is consistent with the presence of dense shelf regime on the western part of the Antarctic Peninsula. At $\mathrm{PM}$ and $\mathrm{KN}$, that is, upstream of the dense water formation, the seasonal amplitude of temperature variations is maximum for surface waters. The seasonal cycle at 200 and 700-1,000 $\mathrm{m}$ depth varies in opposite phase because the temperature sensors capture the vertical movements of the WDW layer. The latter is characterized by a temperature maximum at $400 \mathrm{~m}$ depth (Figure $4 \mathrm{a}$ ). Therefore, when it uplifts (deepens), temperature increases (decreases) at $200 \mathrm{~m}$ depth and decreases (increases) at 700-1,000 m depth. Nearby the bottom (panel c2), the seasonal cycle is weaker and in phase with the one at $700-1,000 \mathrm{~m}$ depth. At AP, downstream of the dense water formation region, seasonal temperature variations are maximum at the bottom (panels c2 and c3). While at 700-1,000 m depth temperature variations have no seasonality, a seasonal cycle can still be observed at $200 \mathrm{~m}$ depth (panels a2 and a3) with a weaker amplitude than upstream, that is, at PM and $\mathrm{KN}$. This indicates a decoupling between the surface layer and the dense plume and a weakening of the surface seasonality along the slope. At depth, nearby the bottom, a seasonal signal is found above the 2,000-2,500 $\mathrm{m}$ and 3,000-3,500 $\mathrm{m}$ isobaths (panels $\mathrm{c} 2$ and $\mathrm{c} 3$ ) with 1-month lag in the offshore direction. This seasonal variability is comparable with the one observed at 700-1,000 m depth upstream, at PM (panels b2 and b3), and will be discussed in section 4.4.

Despite the interannual-mean shift in density regime, the seasonal variability in velocity is mainly barotropic along the continental slope (Figure 6). Comparing the seasonal cycles of barotropic velocity suggests that a coherent seasonal acceleration of the barotropic flow exists along the continental slope with a time lag between the 2,000/2,500 and 3,000/3,500 $\mathrm{m}$ isobaths. In fact, with the exception of the 1,000 $\mathrm{m}$ isobath, the seasonal cycle of barotropic velocity is mostly in phase among all sites (Figure 6a). A maximum (minimum) occurs in April/May (between December and February) above the 2,000-2,500 $\mathrm{m}$ isobath while the signal is lagged by 1 -month above the $3,500 \mathrm{~m}$ isobath. However, the seasonal variability above the $2,000 / 2,500$ isobaths is not clear at AP because the amplitude of the seasonal variations progressively decreases from $7 \mathrm{~cm} \mathrm{~s}^{-1}$ at PM to $1-3 \mathrm{~cm} \mathrm{~s}^{-1}$ at AP (panel b2). The decrease in velocity is not valid along the 3,000/3,500 isobath (panel b3) because $\mathrm{KN}_{3500}$ is located near a velocity front. This velocity front is associated with an abrupt change in topography (Figure 4d), which separates offshore and onshore water masses. As the amplitude of the seasonal variability decreases along the continental slope, both the uncertainty in the seasonal cycle and the offshore lag increases. However, the seasonal cycles remain significant at all sites.

The baroclinic velocities are defined as the difference between the absolute velocity and the barotropic component. Theses velocities are shown at the surface and the bottom in Figures $6 \mathrm{~b}$ and $6 \mathrm{c}$, respectively. As the baroclinic structure of the flow shifts from being surface to bottom intensified along the slope, the baroclinic velocities shift from being larger at the surface at PM and $\mathrm{KN}$ to being larger at the bottom of AP. At PM, the amplitude baroclinic velocities varies by $1-6 \mathrm{~cm} \mathrm{~s}^{-1}$ over the year (black line, Figure 6b), lagging the barotropic signal by 1-2 months. Above the 2,000-2,500 $\mathrm{m}$ isobath, they reach a maximum at $200 \mathrm{~m}$ depth and a minimum at the bottom in June (black line, Figures $6 \mathrm{~b} 2$ and $6 \mathrm{c} 2$, respectively). Above the 3,500 $\mathrm{m}$ isobath, the signal is lagged by 3 months at $200 \mathrm{~m}$ depth, and the variations are negligible at the bottom (Figures $6 \mathrm{~b} 3$ and $6 \mathrm{c} 3$, respectively). The data are generally not sufficient to fully assess the seasonal variability at KN. Nevertheless, it is worth noting that the baroclinic variability is enhanced between March and June, in phase with the maximum flow speed (i.e., standard error in purple, Figures 6b2 and 6b3). At AP, 
(a) barotropic velocity, ubt
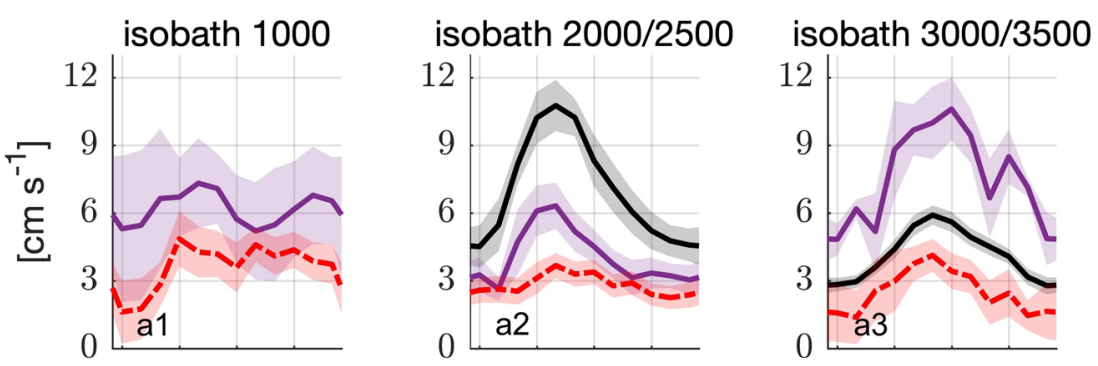

(b) baroclinic velocity at $200 \mathrm{~m}$ depth, u200-ubt
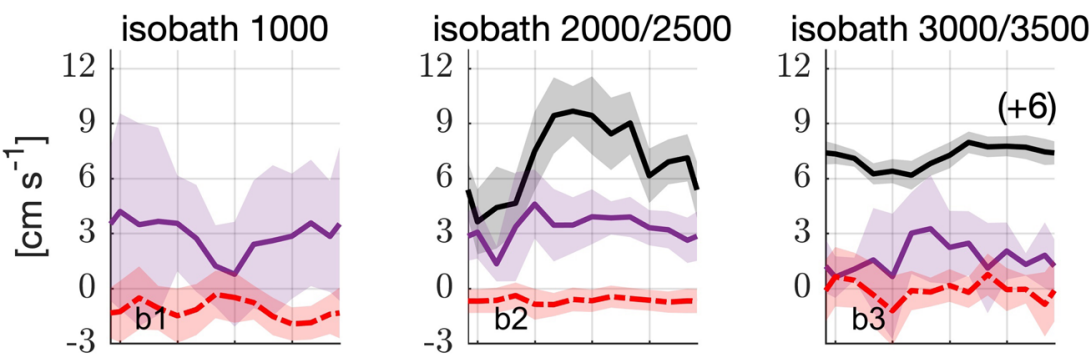

(c) baroclinic velocity at the bottom, ubottom-ubt
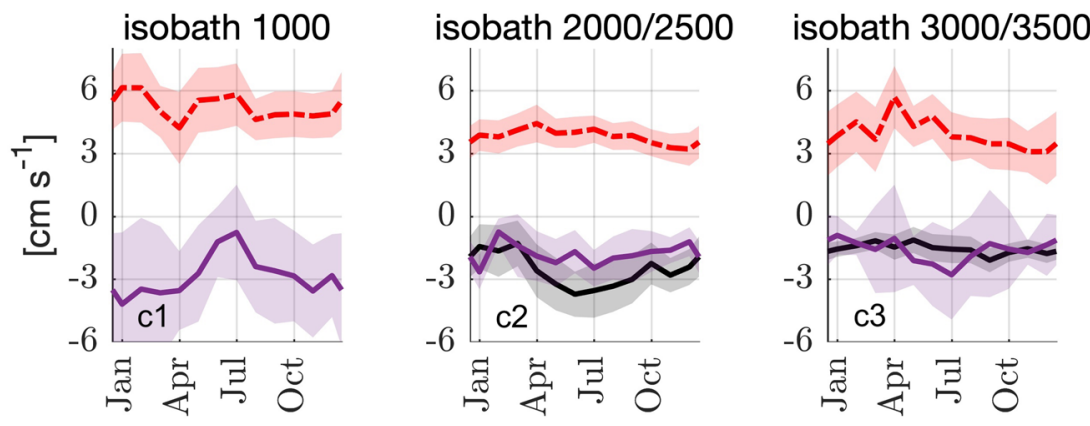

PM

KN ----ーAP

Figure 6. Seasonal cycle of velocities estimated at the three study sites above the 1,000;2,000/2,500; and 3,000/3,500 m isobaths. (a) depth-averaged velocity, (b) baroclinic velocity at $200 \mathrm{~m}$ depth, and (c) baroclinic velocity near the bottom. Shaded areas represent the respective standard errors. The barotropic component is defined as the full-depth average. The baroclinic component is defined as the difference between the absolute velocity and the barotropic velocity. The baroclinic seasonal cycle in the middle right panel (black line) is shifted by $6 \mathrm{~cm} \mathrm{~s}^{-1}$ to avoid overlap with the other cycles.

downstream of the dense water formation region, the analysis suggests a baroclinic seasonal cycle exists at the bottom. The signal is maximum (minimum) in April (December/January) at the 2,000-2,500 $\mathrm{m}$ and $3,500 \mathrm{~m}$ isobath (dashed line, Figures $6 \mathrm{c} 2$ and $6 \mathrm{c} 3$ ) and its amplitude matches the barotropic variability. However, our conslusions are limited by the uncertainty of the baroclinic cycles, which is larger than at PM and $\mathrm{KN}$. No seasonality is observed at $200 \mathrm{~m}$ depth, nor along the $1,000 \mathrm{~m}$ isobath at all locations and depths.

\subsubsection{Relation to the Surface Stress}

The input of dense waters from the continental shelves is expected to be the main driver of interannual-mean changes along slope. Nevertheless, the weakening of both the Ekman pumping and along-slope surface stress downstream of KN (Figures 1 and 7a) can partially explain the ascent of the pycnocline depth between $\mathrm{KN}$ and AP. The Ekman pumping reaches up to $100 \mathrm{~m} \mathrm{yr}^{-1}$ east of PM, whereas it is smaller than $20 \mathrm{~m} \mathrm{yr}^{-1}$ between $\mathrm{KN}$ and AP. In the BCS vicinity, the along-slope surface stress reaches up to $0.12-0.16 \mathrm{~N}$ 
(a) Annual mean surface stress projected along-slope, $\tau$

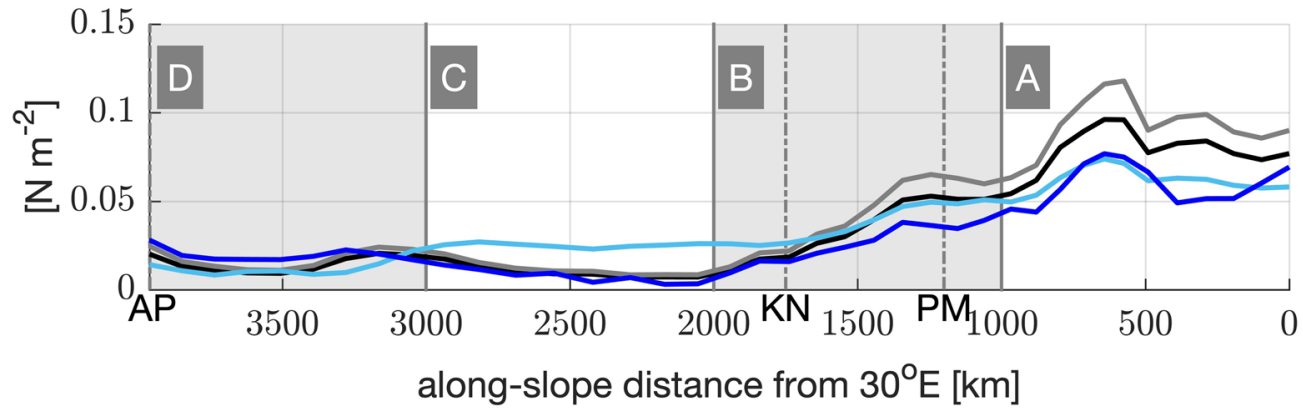

$\longrightarrow \tau_{w} \longrightarrow \tau_{w i c} \longrightarrow \tau_{\text {wicv }} \longrightarrow \tau_{\text {model }}$

\section{(b) Seasonal cycle}

Gyre-scale, wek
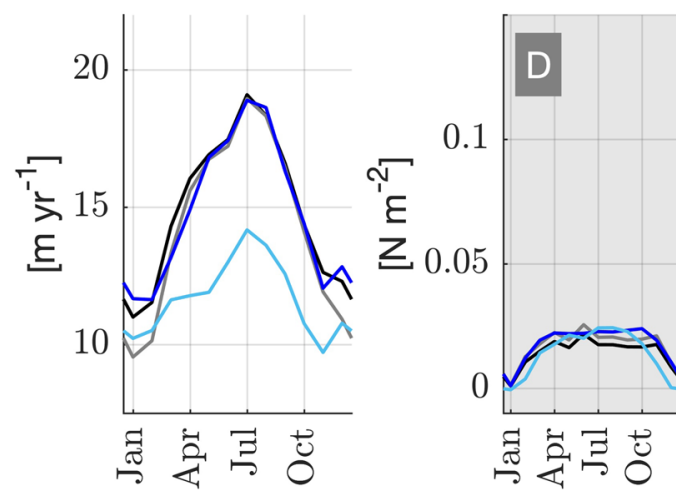

Along-slope surface stress, $\tau$

Figure 7. Variability in surface stress. (a) Interannual-mean surface stress averaged across the continental slope within the $100 \mathrm{~km}$ wide band centered on the 2,500 $\mathrm{m}$ isobath. (b) Seasonal cycle of Ekman pumping and surface stress projected along-slope. The Ekman pumping is averaged over the gyre, south of the zero-crossing given in Figure 1. The along-slope stress is averaged across and along the continental shelf break within domains A-D. Four different estimates of surface stress are compared to represent its uncertainty. $\tau_{w}, \tau_{w i c}, \tau_{\text {wicv }}$, and $\tau_{\text {model }}$ are defined in the manuscript's body in section 2.3. The standard errors associated with each product are negligible for the Ekman pumping and less than $0.015 \mathrm{~N} \mathrm{~m}^{-2}$ for the along-slope stress.

$\mathrm{m}^{-2}$ upstream of $\mathrm{KN}$, whereas it becomes negligible downstream. This implies a weakening of the downwelling across the continental slope downstream of $\mathrm{KN}$, leading the pycnocline to slope upward toward the AP (section 3.1.1).

The seasonal variability of velocity and temperature associated with the surface stress consists of two components: (i) The Ekman pumping averaged over the gyre, which controls sea-level anomalies and the upwelling in the center of the gyre and (ii) the along-slope surface stress averaged across the continental slope, which controls the sea-level anomalies and the downwelling at the coast. These components determine the across-slope gradient of sea-level and density anomalies, which sets the flow strength and the baroclinic structure of the flow, respectively. The gyre scale Ekman pumping exhibits a seasonal cycle with a maximum (minimum) in June (December-January), independently of the method used to estimate the surface stress (Figure $7 \mathrm{~b}$, right panel). Only the magnitude differs. This cycle peaks 1-2 months later than the depth-averaged flow strength (Figures $6 \mathrm{a} 2$ and 6a3). This suggests that the barotropic flow is rather controlled by the surface stress or/and by the change in thermohaline properties along the continental slope than by the gyre-scale surface stress. The seasonal cycle of along-slope surface stress differs according to the stress formulation (Figures $7 \mathrm{a}$ and $7 \mathrm{~b}$ panels $\mathrm{A}-\mathrm{D}$ ). Regarding $\tau_{\text {wic }}$, the along-slope surface stress varies by $0.03-0.05 \mathrm{~N} \mathrm{~m}^{-2}$ over the year. The seasonal cycle is indistinct upstream of PM (region A) and it reaches a maximum (minimum) in winter (summer) downstream. Contrastingly, the seasonal signal peaks in winter at PM, for either $\tau_{w}, \tau_{\text {wic }}$ or $\tau_{\text {model }}$. Also, the along-slope surface stress peaks in November between $20^{\circ} \mathrm{W}$ 

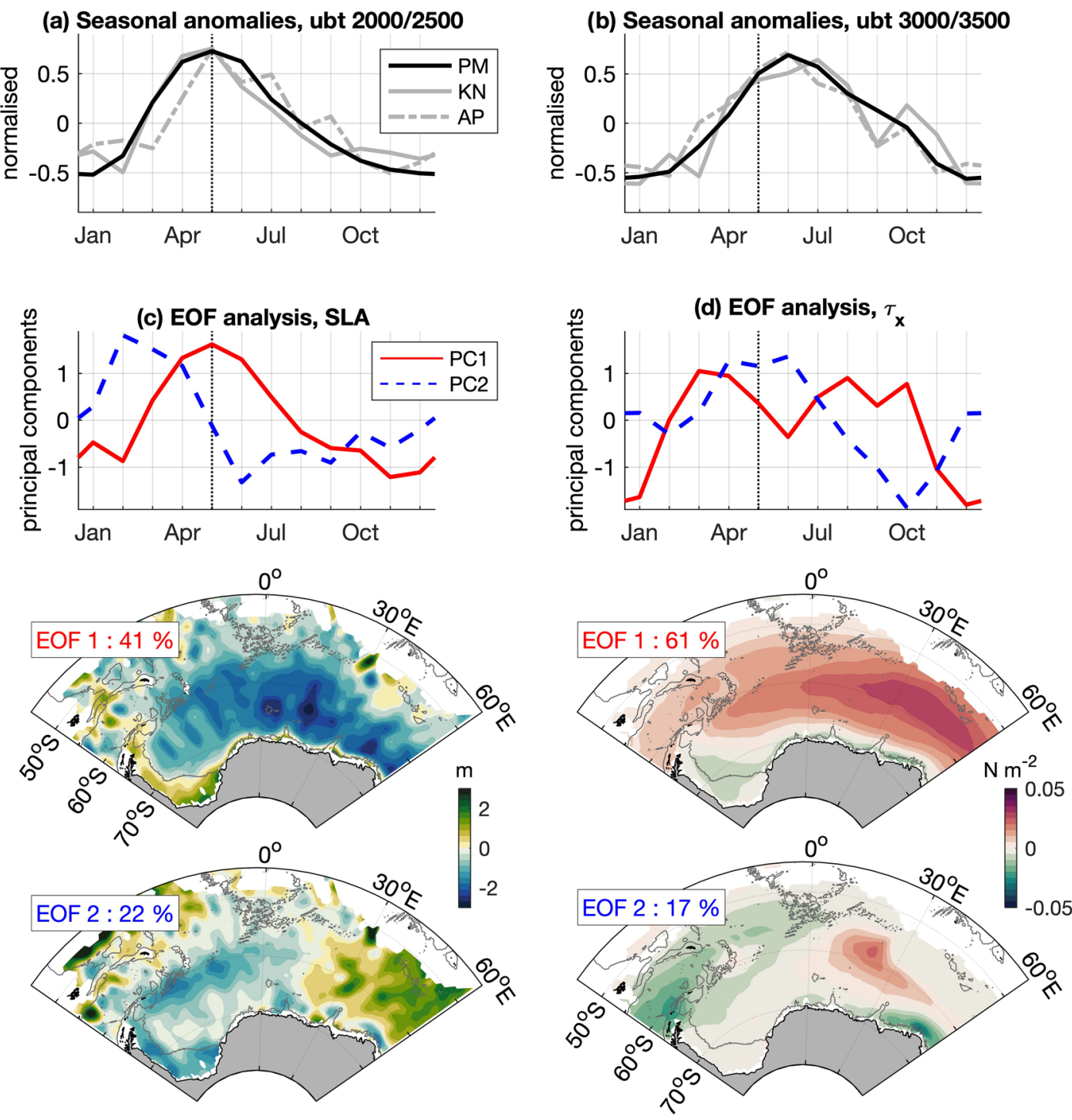

Figure 8. Comparison between the phase of the barotropic flow (ubt) at the three study sites, the variability in sea-level anomalies (SLA) and the variability in zonal surface stress. Panels (a) and (b) show the normalized barotropic velocity along the 2,000/2,500 and 3,000/3,500 m isobaths, respectively. Panels (c) and (d) show the EOF analysis on sea-level anomalies and zonal stress $\left(\tau_{\text {wicv }}\right)$, respectively. The two first-principle components and their corresponding modes are presented from top to bottom.

and $60^{\circ} \mathrm{W}$ instead of peaking in winter (regions B and C on Figure $7 \mathrm{~b}$ ). Ultimately, the uncertainty in sea ice/ocean momentum transfer is too large to directly match the local averages in seasonal surface stress with the seasonal cycles of temperature and velocity given in Figures 5 and 6.

\subsection{Coherent Seasonal Acceleration of the Barotropic Flow Along the Continental Slope}

The coherent seasonal acceleration of the barotropic flow and its across-slope lag is confirmed along the 2,000/2,500 and 3,000/3,500 isobaths on Figures $8 \mathrm{a}$ and $8 \mathrm{~b}$. The barotropic signal is well captured at KN, despite the sparsity of the data (Figure 3). In fact, the seasonal barotropic signal from our data compilation shows a similar seasonality with data from a more recent year-long mooring deployed $350 \mathrm{~km}$ downstream of our study site (Graham et al., 2013) (Figure S1). This suggests that opposingly to the baroclinic cycle, the seasonal acceleration of the barotropic flow is consistent over the years at this study location. An EOF analysis shows that the along-slope seasonal acceleration of the flow is also present in the variability of SLA. The first mode of SLA, which is associated with an across-slope gradient along the slope (Figure 8c), is in phase with the seasonal cycle of barotropic velocity along the 2,000/2,500 $\mathrm{m}$ isobath ( $r=1$ at $0 \mathrm{lag}$ ). 
This confirms the existence of a coherent seasonal cycle of the geostrophic flow intensity. The second mode, which is associated with seasonal changes in the zonal gradient of SLA has a maximum correlation of $r=0.8$ at 2 months lag ( $r=-0.1$ at 0 lag). This implies that the meridional flow associated with the zonal gradient of SLA is at least partly decoupled from the barotropic seasonal cycle.

The seasonal analysis in surface stress shows a maximum input upstream of the Prime Meridian (Figure $7 \mathrm{~b}$ ). Except for $\tau_{\text {wicv }}$, the surface stress increases between January and May, in phase with the barotropic flow. Anticipating a connection between the zonal stress and the barotropic flow, we used an EOF approach to identify the gyre-scale pattern of zonal stress. The first mode of variability shows a meridional oscillation of the zonal winds (Figure 8d). It correlates with the seasonal cycle of barotropic flow along the $2,000 / 2,500$ isobath with $r=0.5$ at $0 \mathrm{lag}$, but their respective seasonality differs. The second mode, which is associated with a cyclonic momentum input on the eastern side of the gyre in autumn, presents a similar seasonal cycle with the barotropic flow along both isobaths, with $r=0.8$ at 0 lag along the 2,000/2,500 m isobath. This correlation suggests that the along-slope surface stress, which controls the cross-slope gradient of SLA on the eastern margin, relates to the barotropic seasonal cycle for all three sites. This result is valid for all four surface stress estimates (Figure S2I).

\subsection{Correlation Between the Barotropic Variability at the Tip of Antarctic Peninsula and the Surface Stress}

Our previous analysis computed seasonal cycles independently from each other and compared their variability. Such comparisons reveal if patterns covary in time but does not provide compelling evidence for causal linkages. To test for a causal relationship between momentum input in the eastern Weddell sea and seasonal acceleration of the barotropic flow at AP, we correlated the velocities recorded at AP with the different components of surface stress (Figure 9). The seasonal variability is barotropic above the dense plume (Figure 6b2) and we chose the along-slope velocity at $750 \mathrm{~m}$ depth at $A P_{2500}$ (u750) to monitor the barotropic variations. This choice allowed constructing a 10-year long time series rather than 5 years by constructing monthly barotropic time series. To avoid spurious correlations, a mean value was subtracted for each 2-hourly interval period. Indeed, a shift in velocity associated with a change in current meter depth would artificially bias the correlation toward low frequencies. Finally, the records were averaged monthly to obtain a monthly mean time series, which covers 2005 to 2015 (u750, Figure 9a).

The relationship between the cyclonic momentum input on the eastern margin of the study area and the seasonal acceleration of the barotropic flow is confirmed for three surface stress products (Figure $9 \mathrm{~b}$ ). The correlation between $\mathrm{u} 750$ and westerly winds offshore $(r>0.2)$ /easterly winds along the continental mar$\operatorname{gin}(r<-0.2)$ is significant for $\tau_{w}, \tau_{w i c}$. For $\tau_{w i c v}$, the correlation is significant with the westerly winds only. A significant correlation associated with the across-slope surface stress is also found on the western margin for $\tau_{w}, \tau_{w i c}$, and $\tau_{\text {model }}(r>0.2)$. However, an increase in surface stress in the offshore direction cannot relate directly to the acceleration of the barotropic flow. $\tau_{\text {wic }}$ and $\tau_{\text {model }}$ show a significant correlation associated with the northward stress along the western margin $(r>0.2$, Figure 9c). Nevertheless, no coastline can support the downwelling associated with the onshore Ekman transport there. The strongest correlation between u750 and Ekman pumping (wek) is found upstream of the Prime Meridian, between $60^{\circ} \mathrm{S}$ and $70^{\circ} \mathrm{S}$ ( $\tau_{w}, \tau_{w i c}$, and $\tau_{w i c v}$, Figure $9 \mathrm{~d}$ ). This result is consistent with a summer intensification of the easterly and westerly winds, which control the upwelling of waters offshore of the continental slope and the downwelling associated with the easterly winds at the continental margin (Figure 8d). The ocean does not immediately respond to the Ekman pumping and its intensification needs to last a few months to explain an acceleration of the flow. For $\tau_{w}, \tau_{w i c}$, and $\tau_{\text {wicv }}$, even though $\mathrm{u} 750$ is correlated with downwelling associated with negative Ekman pumping at AP $(r<-0.2$, Figure 9), no lagged correlation exists. The correlation between u750 and the Ekman pumping persists up to 2 months upstream of $20^{\circ} \mathrm{E}$ (lagged correlation in Figure S5), confirming that the seasonal acceleration of the barotropic flow is correlated with an increase in atmospheric forcing that slowly propagates westward in front of the eastern margin. Even though this correlation is not found in $\tau_{\text {model }}$, the connection between eastern atmospheric input and barotropic seasonality is found when averaging the monthly variability over the years (EOF analysis in Figure S2). This suggests a larger interannual variability in the model and also confirms the large uncertainty in ice-ocean momentum transfer. It also confirms the large uncertainty on the momentum transfer between ice-ocean.

In summary, the correlation analysis suggests that the along-slope barotropic flow mainly responds rapidly to a seasonal convergence of water masses associated with the surface stress on the eastern gyre. 


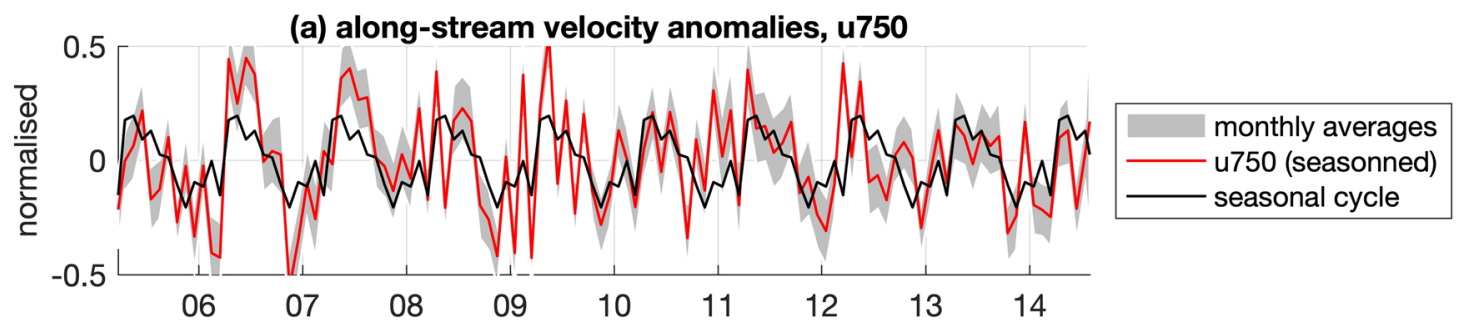

(b) correlation: $u 750, \tau_{x}$

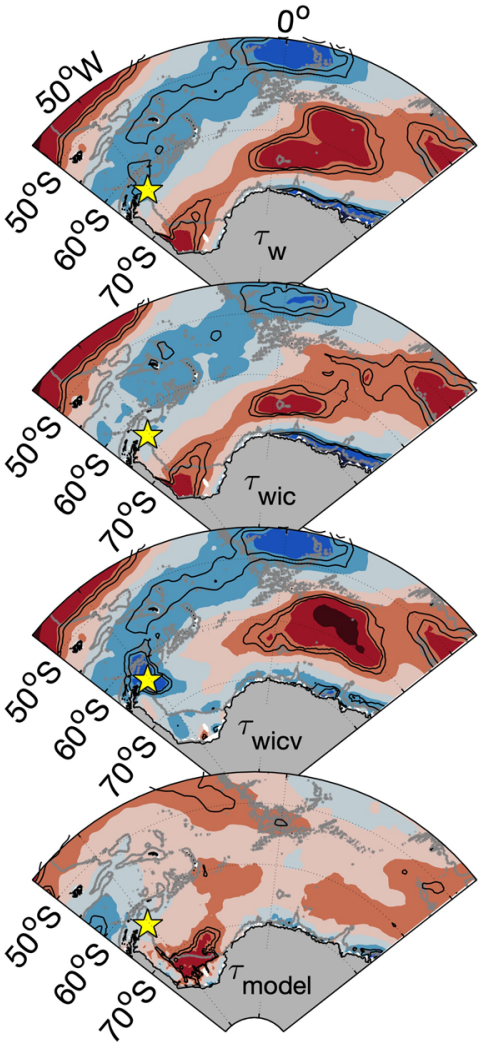

(c) correlation: $u 750, \tau_{y}$

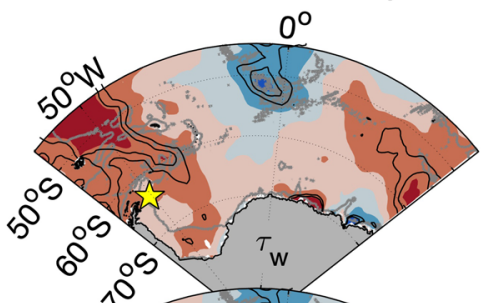

(d) correlation: u750, wek
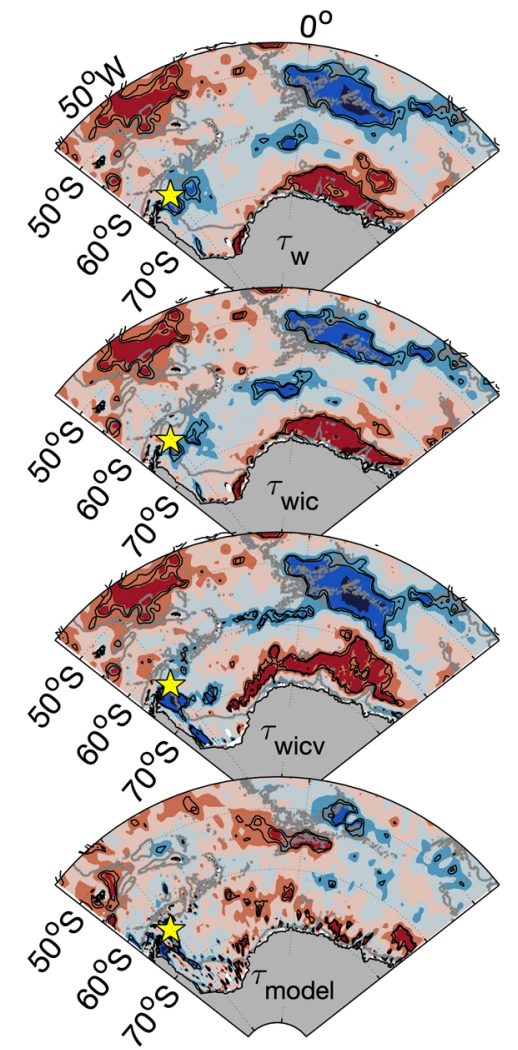

0.2

0.4

Figure 9. Zero lag correlation maps between monthly mean velocities observed between 2005 and 2015 at $A P_{2500}$ and the different components of surface stress. The velocity at $750 \mathrm{~m}$ is used as a proxy for the barotropic variations. The correlation maps are computed for four different estimates of surface stress, as described in section 2.3. (a) Monthly mean velocity at $750 \mathrm{~m}$ depth. (b-d) Correlation between $\mathrm{u} 750$ and the zonal stress, meridional stress, and Ekman pumping, respectively. The star shows the position of $A P_{2500}$. The black contours represent $90 \%$ and $95 \%$ confidence interval.

Nevertheless, it is not possible to fully assess if this convergence of water masses is controlled by the open ocean Ekman pumping or by the southward Ekman transport. Indeed, the spatial distribution in surface stress depends on the momentum transfer between ice and ocean, which is partly unknown.

\section{Discussion}

\subsection{Annual Mean Shift in Flow Regime Along Slope}

Although the along-slope densification of the water masses is well established (Gill, 1973), we have provided new insight into the along-slope shift in density regime, by combining historical data from a variety of sources from along the continental slope of the Weddell Sea. The along-slope cooling and salt enrichment of the shelf waters shown in the climatological sections (Figure 4) attest the importance of the DML and the FRIS continental shelves for shifting from a fresh to a dense shelf regime. Along the pathway of 
the BCS, modified Warm Deep Water (mWDW) exchanges properties with the less saline Eastern Shelf Water formed along the narrow continental shelf of Dronning Maud Land, and with the High Salinity Shelf Water (HSSW) and Ice Shelf Water (ISW) formed on the continental shelves in front of the Filchner-Ronne Ice Shelf (FRIS) and Larsen Ice Shelf (LIS) through surface thermohaline forcing and convection (Nicholls et al., 2009). This leads to the formation of Weddell Sea Deep Water (WSDW) and the flow of Weddell Sea Bottom Water (WSBW) along the western continental slope. This dense water outflow may subsequently create instabilities that foster transport of WDW onto the continental shelf as suggested by an idealized model simulations (Stewart \& Thompson, 2016). Meanwhile, the surface stress weakens downstream of KN and, in the absence of coastline, the downwelling of lighter water at the coast associated with the Ekman transport reduces. (Mosby, 1934; Nøst et al., 2011; Zhou et al., 2014). Therefore, the BCS dynamics change from being directly driven by atmospheric processes along the DML coast (Hattermann, 2018; Núñez Riboni \& Fahrbach, 2009) to being dominated by continental shelf processes downstream of the FRIS. The density input from the continental shelves and the weakening of the surface stress lead the pycnocline and the halocline to slope upward toward the AP. Also, the cross-slope density gradient, which is negative upstream of $\mathrm{KN}$, weakens at the surface and reverses at the bottom toward the AP. In the end, the along-slope shift from a fresh to a dense shelf regime (Thompson et al., 2018) results in a reversal of interannual-mean baroclinic shear along the slope. Note that a number of other processes shape the boundary current system. For instance, $\mathrm{KN}$ is an area of complex topography where the flow is still influenced by upstream variations (Graham et al., 2013; Heywood et al., 1998) and the AP is an area where barotropic jets, unresolved in our analysis, are known to exist (Stewart \& Thompson, 2016; Thompson \& Heywood, 2008).

\subsection{Seasonal Acceleration of the Barotropic Flow}

Our analysis revealed that a coherent seasonal cycle of the barotropic flow exists along the slope, with 1-month lag in the offshore direction. The seasonal cycle is captured upstream and downstream of the dense water formation regions and its coherency is confirmed in the variability in sea-level anomalies. While an along-slope shifts in the baroclinic structure of the flow exist, the variability observed above the dense plume remains barotropic at AP. In fact, the barotropic cycle accounts for more than $50 \%$ of the variability in bottom velocity at the 2,500 and 3,500 $\mathrm{m}$ isobaths (Figure 6). This suggests that most of the seasonal variability in bottom water transport is associated with the seasonal acceleration of the barotropic flow along the slope. However, current meter measurements are also needed at locations where the dense water outflow is the most energetic, that is, where the bottom slope is the steepest, to quantify the seasonal transport above and inside the dense plume.

The cross-slope phase lag between the 2,000/2,500 and 3,000/3,500 $\mathrm{m}$ isobaths is found at the three study sites. However, the seasonal acceleration/deceleration of the flow is slightly offset toward winter at AP. This suggests a weakening of the across-slope phase lag toward the Antarctic Peninsula, which can be explained by the seasonal changes in thermohaline properties at the surface. As sea ice melts during austral summer, the across-slope density gradient between light surface water and deep water increases (Hattermann, 2018). Theoretically, this would modulate the cross-slope gradient of sea-level anomalies that relates to the geostrophic flow intensity and temporally shifts the maximum depth-averaged flow strength toward summer. Such mechanisms would be enhanced onshore and could both explain why an across-slope seasonal lag exists along the slope and why the maximum surface stress lags the maximum bottom velocities by few months at $P M_{2000}$ and $K N_{2500}$ (Figure 6). At AP, the across-slope transport of surface water associated with the along-slope surface stress is weaker, reducing the steric contribution to the sea-level anomalies at the coast and limiting the shift toward summer along the 2,000/2,500 isobaths. Alternatively, Núñez Riboni and Fahrbach (2009) argued that the local modulation of surface momentum input by the sea ice explains the lag across slope. However, the spatial uncertainty on the surface stress remains too large to comment on their hypothesis. Seasonal changes at the gyre inflow (Cisewski et al., 2011; Ryan et al., 2016) could also modify the seasonality across slope. However, an increase in flow speed over the continental slope might result in an increase in flow speed, offshore of the continental slope, further downstream. Thus, it would not explain why a phase lag remains at AP. In the end, both uncertainty on the barotropic variations and the surface stress are too large to conclude about the cross-slope lag. 


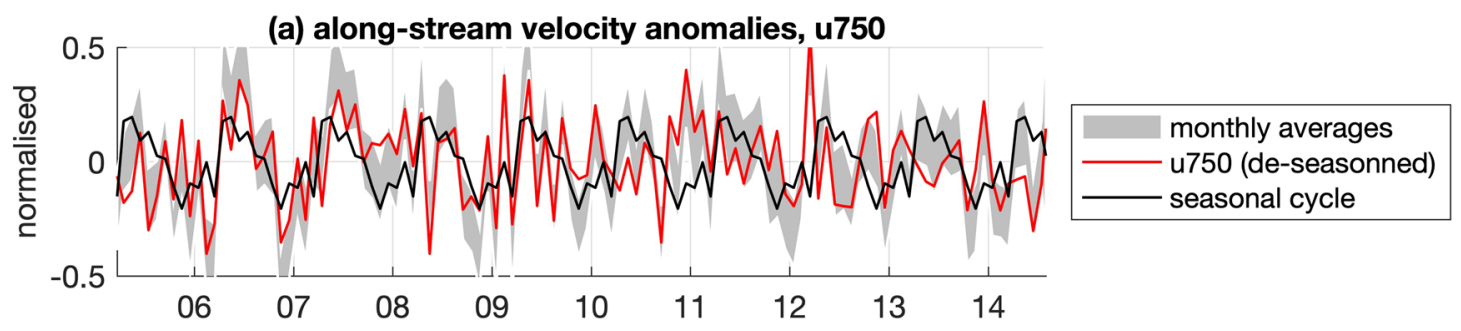

(b) correlation: $u 750, \tau_{x}$

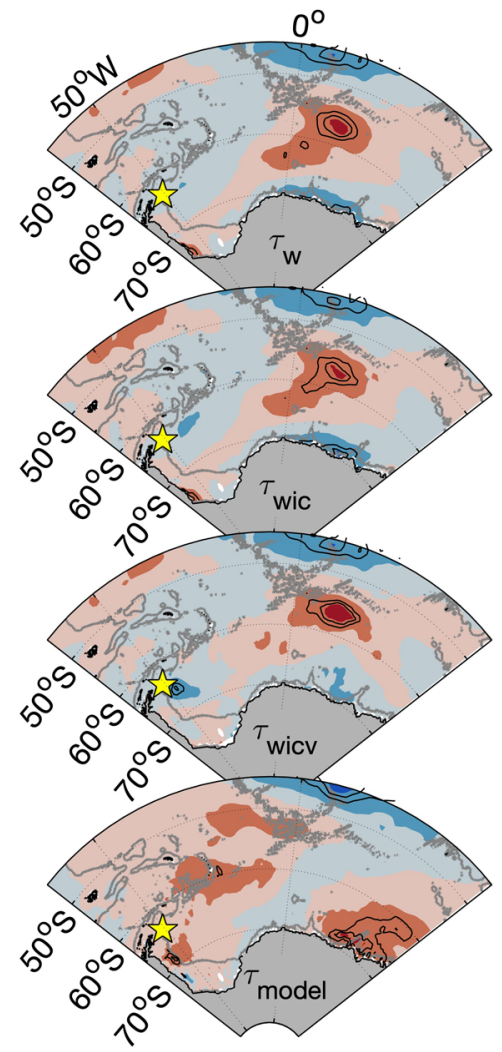

(c) correlation: $u 750, \tau_{y}$
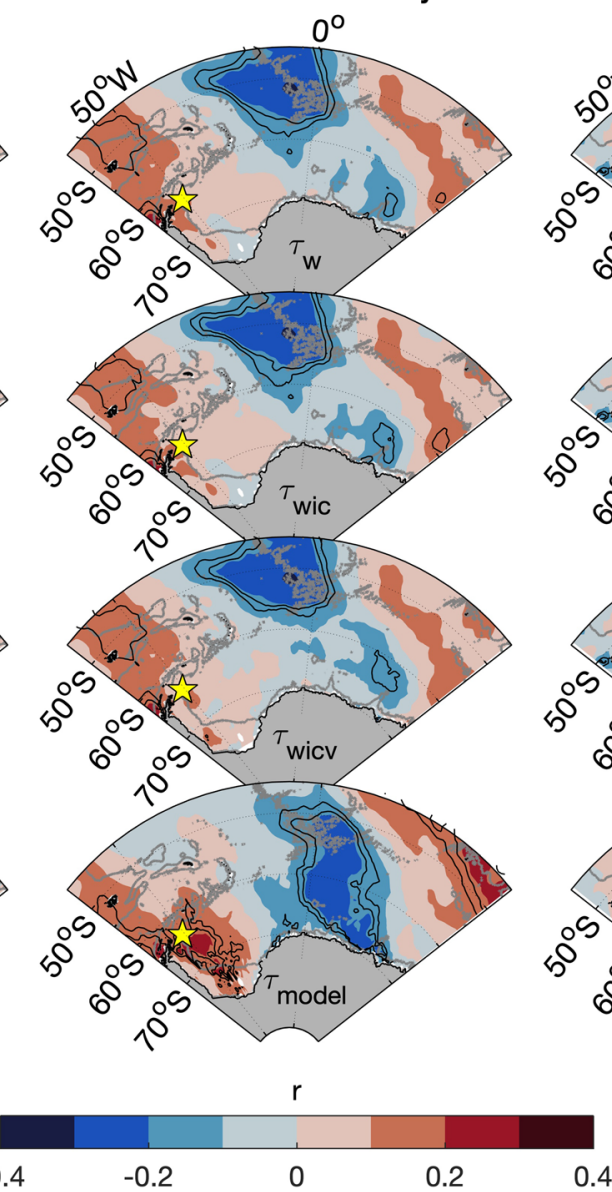

(d) correlation: u750, wek
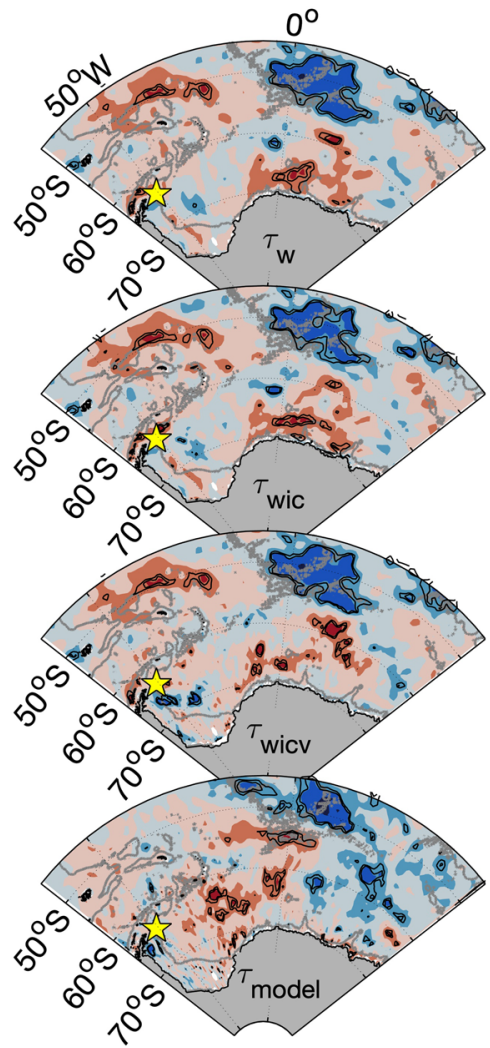

0.4

Figure 10. Same as in Figure 9 but the 0 lag correlation is made between the deseasoned variability in velocity and surface stress (difference between monthly averages and seasonal cycle).

\subsection{Teleconnection Between the Barotropic Flow and the Eastern/Northeastern Weddell Sea Winds}

The seasonal cycle in barotropic velocity is not strongly correlated to spatial averages of surface stress and Ekman pumping, suggesting that neither the local surface stress nor the gyre-scale Ekman pumping directly control the barotropic fluctuations. To corroborate this statement, we investigated the spatial variability in surface stress, using an EOF approach (Figure 8) and spatially correlating the monthly variability in surface stress with the monthly variability in barotropic velocity (Figure 9). Both analyses relate the seasonality of the barotropic flow with a surface momentum input on the eastern side of the gyre. This nonlocal correlation suggests that a teleconnection exists between the atmospheric momentum input on the eastern side of the gyre and the barotropic flow. This might be explained by the conservation of planetary vorticity along closed topographic contours (Isachsen et al., 2003) and the rapid westward propagation of sea-level anomalies of a few centimetres height via barotropic Kelvin-Rossby waves (Hughes \& Meredith, 2006; Spence et al., 2017). Although the significance is less clear, the patterns found in the deseasoned correlation maps are 
comparable with the seasoned correlation (Figures 10 and 9, respectively). In particular, the zonal stress and the Ekman upwelling (downwelling) in the eastern inflow branch of the Weddell Gyre (and north of it in the ACC) indicates an even further upstream driver (Figures $10 \mathrm{~b}$ and 10d). This suggests that the variability in barotropic transport is indeed connected with remote forcing. In fact, Naveira Garabato et al. (2019) has already shown the connection between sea-level anomalies and circumpolar winds and our results support their discussion with in situ observations. Also, the correlation between barotropic flow and surface stress is valid, regardless of whether or not sea ice concentration/velocity were accounted for in the method used to calculate the surface stress. This highlights that the wind is the main driver of variability, although the sea ice significantly modulates the surface stress locally.

\subsection{Baroclinic Response to Seasonal Forcing}

The baroclinic variability differs at each study site, showing a larger sensitivity to local variations than for the barotropic signal. At PM, the baroclinic variations lag the barotropic velocity along the 2,500 $\mathrm{m}$ isobath and thus, the surface stress, by 1 or 3 months, as shown by Núñez Riboni and Fahrbach (2009). This time scale is consistent with the temporal adjustment of the pycnocline slope via baroclinic instability in response to an increase in Ekman transport modulated by thermohaline forcing (Hattermann, 2018). This also confirms the probability of fast barotropic signals to propagate from this location. Downstream of PM, the seasonal cycles of velocity at the surface were weak compared to the depth-averaged signal. However, at KN, velocity records collected at the 1,500 $\mathrm{m}$ isobath (Heywood et al., 2012) show that the top to bottom shear varied by 15 to $20 \mathrm{~cm} \mathrm{~s}^{-1}$ between February and October 2010. It confirms that the baroclinic variations are stronger in this region than the ones shown by our analysis (Hattermann, 2018). In fact, our study uses velocity records at four depths over the 2,500 $\mathrm{m}$ isobath, offshore of the slope front. It allows for a good estimation of the depth-averaged flow speed, but prevents us from capturing the seasonal baroclinic signal that is more pronounced closer to the coast. The shift in flow regime discussed in section 4.1 explains the weak variability observed at AP. As the continental slope widens, the surface stress decreases, resulting in a weaker variability in temperature and velocity in the vicinity of the pycnocline depth (Figures 5 and 6).

The variability in baroclinic velocity and surface stress are not observed in the temperature variations at $200 \mathrm{~m}$ depth, which in fact, is not a good indicator for density variations. In the Weddell Sea, the horizontal density gradient, which determines the baroclinic variations, differs from the temperature gradient because relatively warm and salty WDW is present at intermediate depth (Figure 4). Moreover, the variations in surface stress cannot directly relate to the temperature since it also varies seasonally as a function of the thermohaline forcing. Below $200 \mathrm{~m}$ depth, the density field follows the temperature and a seasonal cycle is captured at several locations (Figure 5, solide blue lines). This suggests that a common mechanism could explain the baroclinic fluctuations at depth. Using an idealized two-layer model, Su et al. (2014) showed that the gyre-scale surface stress in balance with the across-slope eddy flux triggers the seasonal oscillations of isopycnals at AP. The authors also show that the phase of these oscillations depends on the isopycnal slope which varies across-slope. Except for the amplitude, the solution of Su et al. (2014) is valid for any outcropping isopycnal. This could explain why a seasonal signal is observed at the different locations and depths, and how its phase depends on the mooring location. The baroclinic seasonal response associated with the coastal propagation of Kelvin-Rossby waves could also explain these fluctuations. However, warming (cooling) at the subsurface associated with the propagation of negative (positive) SLA discussed by Spence et al. (2017) on interannual time scales is not clear on seasonal time scales. In fact, the seasonal cycle of temperature at $200 \mathrm{~m}$ is decorrelated from the variability in SLA. Additionally, the variations downstream of FRIS can be controlled by the local adjustments of the flow to the surface forcing and the export of dense water from the ice shelves (Gordon et al., 2010; Meredith et al., 2011; Wang et al., 2012; Van Caspel, 2016), explaining the maximum velocity observed at the bottom in autumn. Thus, the baroclinic adjustments remain unclear. High-frequency current meters overlapping in time need to be deployed within the slope front to estimate the along-slope propagation of the signal. Observations on the western continental shelf are also needed to understand the variability in the dense plume and isolate its main drivers.

\section{Summary and Conclusion}

Past studies show that the boundary current system in the Weddell Sea contributes to both the export of deep and bottom waters toward lower latitudes, and the flow of WDW toward the Filchner Ronne Ice Shelf cavities. Although the seasonality along the continental slope of the Weddell Sea has been investigated before 
at specific locations, here we present a coherent understanding of the entire boundary current system. This study combines multiplatform historical data at different locations, providing an interannual-mean view of the boundary current system and explores its adjustment on seasonal time scales.

We confirm that the geostrophic flow reverses its interannual-mean vertical shear between KN and AP, which is characteristic for an overturning circulation forced by the dynamics on the continental shelf. The along-slope decrease in surface stress might also contribute to the shift in flow regime. A coherent seasonal acceleration of the barotropic flow is observed at all sites with a maximum speed in austral autumn, associated with a coastal rise of SLA. The comparison between the SLA and the surface stress field indicates that the barotropic flow adjusts to a momentum input on the eastern/northeastern side of the gyre. Such teleconnection implies that changes in the surface stress field trigger a fast large-scale response in the ocean. At the tip of the Antarctic Peninsula, the barotropic flow significantly contributes to the seasonal velocity in the dense plume. Thus, by controlling the seasonal acceleration of the barotropic flow, the surface stress might remotely modulate the export of dense water from the Weddell Sea on monthly time scales (Meijers et al., 2016).

Several methods of calculation of surface stress are compared to estimate its uncertainty, either considering the wind velocity only, accounting for the sea ice modulation of the stress, or using sea ice ocean model output. We find large differences in local-averages at the coast. However, the relationship between barotropic flow strength and surface stress variability on the eastern gyre is valid no matter the method. This shows that the main driver of barotropic seasonality is the wind even though sea ice significantly modulates the surface stress in marginal ice zones. Further research integrating the contribution of the seasonal variations of buoyancy forcing at the continental shelf is needed to understand the seasonal baroclinic fluctuations.

\section{Data Availability Statement}

This study uses historical data collected on board of R/V Polarstern between 1986 and 2017 (Grants AWI_PS89_01, AWI_PS96_01, and AWI_PS103_01), freely available online (https://www.pangaea.de). The Argo float data were collected and made freely available by the International Argo Program and the national programs that contribute to it (http://www.argo.ucsd.edu, http://argo.jcommops.org). The marine mammal data were collected and made freely available by the International MEOP Consortium and the national programs that contribute to it (http://www.meop.net).

The wind data were made freely available by the European Centre for Medium-Range Weather Forecasts, ECMWF (https://www.ecmwf.int/en/forecasts/datasets/reanalysis-datasets/era-interim). The sea-ice concentration and sea-ice drift data were made freely available by the National Snow \& Ice Data Center, NSIDC (https://nsidc.org/data/NSIDC-0051/versions/1; https://nsidc.org/data/NSIDC-0116/versions/4).

\section{Acknowledgments}

Most of the moorings used for this work were part of the Hybrid Antarctic Float Observation System (HAFOS). The authors would like to thank the Natural Environment Research Council (Grant NE/E012965/1) and Karen Heywood for sharing the mooring data collected at Kapp Norvegia for the SASSI project and used to discuss our results (https:// www.bodc.ac.uk/data/). We would like to thank the three reviewers who found time to provide thorough and insightful comments during this difficult period of time. The authors would finally like to thank Ralph Timmermann for his useful discussion about the surface stress and for providing model output, and Krissy Reeve for improving the scientific writing. One of the authors (Le Paih) was supported by the grant CA 1687/1-1 funded by the Deutsche Forschungsgemeinschaft (DFG).

\section{References}

Argo (2017). Argo float data and metadata from global data assembly centre (argo gdac). seanoe. https://doi.org/10.17882/42182 Armitage, T. W. K., Kwok, R., Thompson, A. F., \& Cunningham, G. (2018). Dynamic topography and sea level anomalies of the Southern Ocean: Variability and teleconnections. Journal of Geophysical Research: Oceans, 123, 613-630. https://doi.org/10.1002/2017JC013534

Årthun, M., Nicholls, K. W., Makinson, K., Fedak, M. A., \& Boehme, L. (2012). Seasonal inflow of warm water onto the southern Weddell Sea continental shelf, Antarctica. Geophysical Research Letters, 39, L17601. https://doi.org/10.1029/2012GL052856

Böhme, L., \& Send, U. (2005). Objective analyses of hydrographic data for referencing profiling float salinities in highly variable environments. Deep Sea Research Part II: Topical Studies in Oceanography, 52(3-4), 651-664. https://doi.org/10.1016/j.dsr2.2004.12.014

Cavalieri, D. J., Parkinson, C. L., Gloersen, P., \& Zwally, H. J. (1996). Sea ice concentrations from Nimbus-7 SMMR and DMSP SSM/I-SSMIS passive microwave data, Version 1. Boulder, Colorado, USA: NASA National Snow and Ice Data Center Distributed Active Archive Center. https://doi.org/10.5067/8GQ8LZQVL0VL

Cisewski, B., Strass, V. H., \& Leach, H. (2011). Circulation and transport of water masses in the Lazarev Sea, Antarctica, during summer and winter 2006. Deep Sea Research Part I: Oceanographic Research Papers, 58(2), 186-199. https://doi.org/10.1016/j.dsr.2010.12.001

Daae, K., Darelius, E., Fer, I., Østerhus, S., \& Ryan, S. (2018). Wind stress mediated variability of the Filchner trough overflow, Weddell Sea. Journal of Geophysical Research: Oceans, 123, 3186-3203. https://doi.org/10.1002/2017JC013579

Darelius, E., Strand, K. O., Østerhus, S., Gammeslrød, T., Årthun, M., \& Fer, I. (2014). On the seasonal signal of the Filchner Overflow, Weddell Sea, Antarctica. Journal of Physical Oceanography, 44(4), 1230-1243. https://doi.org/10.1175/JPO-D-13-0180.1

Dee, D. P., Uppala, S. M., Simmons, A. J., Berrisford, P., Poli, P., Kobayashi, S., et al. (2011). The ERA-Interim reanalysis: Configuration and performance of the data assimilation system. Quarterly Journal of the Royal Meteorological Society, 137(656), 553-597. https://doi. org/10.1002/qj.828

Dotto, T. S., Naveira Garabato, A., Bacon, S., Tsamados, M., Holland, P. R., Hooley, J., et al. (2018). Variability of the Ross Gyre, Southern Ocean: Drivers and responses revealed by satellite altimetry. Geophysical Research Letters, 45, 6195-6204. https://doi.org/10.1029/ 2018GL078607 
Driemel, A., Fahrbach, E., Rohardt, G., Beszczynska-Möller, A., Boetius, A., Budéus, G., et al. (2017). From pole to pole: 33 years of physical oceanography onboard R/V Polarstern. Earth System Science Data, 9(1), 211-220. https://doi.org/10.5194/essd-9-211-2017

Emery, W. J., \& Thomson, R. E. (2001). Chapter 3-Statistical methods and error handling. In W. J. Emery \& R. E. Thomson (Eds.), Data analysis methods in physical oceanography (pp. 193-304). Amsterdam: Elsevier Science. https://doi.org/10.1016/B978-044450756-3/ 50004-6

Fahrbach, E., Harms, S., Rohardt, G., Schröder, M., \& Woodgate, R. A. (2001). Flow of bottom water in the northwestern Weddell Sea. Journal of Geophysical Research: Oceans, 106(C2), 2761-2778. https://doi.org/10.1029/2000JC900142

Fahrbach, E., Rohardt, G., Schröder, M., \& Strass, V. (1994). Transport and structure of the Weddell Gyre. Annales Geophysicae, 12(9), 840-855. https://doi.org/10.1007/s00585-994-0840-7

Gandin, L. S. (1965). Objective analysis of meteorological fields: GIMIZ, Gidrometeorologicheskoe Izdatelstvo, Leningrad 1963: Transl. from the Russian: Israel Program for scientific Translations.

Gill, A. E. (1973). Circulation and bottom water production in the Weddell Sea. Deep Sea Research and Oceanographic Abstracts, 20(2), 111-140. https://doi.org/10.1016/0011-7471(73)90048-X

Gordon, A. L., Huber, B., McKee, D., \& Visbeck, M. (2010). A seasonal cycle in the export of bottom water from the Weddell Sea. Nature Geoscience, 3(8), 551-556. https://doi.org/10.1038/ngeo916

Graham, J. A., Heywood, K. J., Chavanne, C. P., \& Holland, P. R. (2013). Seasonal variability of water masses and transport on the Antarctic continental shelf and slope in the southeastern Weddell Sea. Journal of Geophysical Research: Oceans, 118, 2201-2214. https://doi.org/10.1002/jgrc.20174

Hattermann, T. (2018). Antarctic thermocline dynamics along a narrow shelf with easterly winds. Journal of Physical Oceanography, 48(10), 2419-2443. https://doi.org/10.1175/JPO-D-18-0064.1

Heywood, K., Locarnini, R. A., Frew, R., Dennis, P., \& King, B. A. (1998). Transport and Water Masses of the Antarctic Slope Front System in The Eastern Weddell Sea. In S. S. Jacobs \& R. F. Weiss Ocean (Eds.), Ice, and Atmosphere: Interactions at the Antarctic Continental Margin (Vol. 75, pp. 203-214). https://doi.org/10.1029/AR075p0203

Heywood, K., Muench, R., \& Williams, G. (2012). An Overview of the Synoptic Antarctic Shelf-Slope Interactions (SASSI) project for the International Polar Year. Ocean Science, 8, 1117-1122. https://doi.org/10.5194/os-8-1117-2012

Hughes, C. W., \& Meredith, M. P. (2006). Coherent sea-level fluctuations along the global continental slope. Philosophical Transactions of the Royal Society A: Mathematical, Physical and Engineering Sciences, 364(1841), 885-901. https://doi.org/10.1098/rsta.2006.1744

Isachsen, P. E., LaCasce, J. H., Mauritzen, C., \& Häkkinen, S. (2003). Wind-driven variability of the large-scale recirculating flow in the Nordic Seas and Arctic Ocean. Journal of Physical Oceanography, 33(12), 2534-2550. https://doi.org/10.1175/1520-0485534

Jullion, L., Garabato, A. C. N., Bacon, S., Meredith, M. P., Brown, P. J., Torres-Valdés, S., et al. (2014). The contribution of the Weddell Gyre to the lower limb of the global overturning circulation. Journal of Geophysical Research: Oceans, 119, 3357-3377. https://doi.org/ 10.1002/2013JC009725

Leach, H., Strass, V., \& Cisewski, B. (2011). Modification by lateral mixing of the warm deep water entering the Weddell Sea in the Maud Rise region. Ocean Dynamics, 61(1), 51-68. https://doi.org/10.1007/s10236-010-0342-y

Lüpkes, C., \& Gryanik, V. M. (2015). A stability-dependent parametrization of transfer coefficients for momentum and heat over polar sea ice to be used in climate models. Journal of Geophysical Research: Atmospheres, 120, 552-581. https://doi.org/10.1002/2014JD022418

Lüpkes, C., Gryanik, V. M., Hartmann, J., \& Andreas, E. L. (2012). A parametrization, based on sea ice morphology, of the neutral atmospheric drag coefficients for weather prediction and climate models. Journal of Geophysical Research: Atmospheres, 117, D13112. https://doi.org/10.1029/2012JD017630

Meijers, A. J. S., Meredith, M. P., Abrahamsen, E. P., Morales Maqueda, M. A., Jones, D. C., \& Naveira Garabato, A. C. (2016). Wind-driven export of Weddell Sea slope water. Journal of Geophysical Research: Oceans, 121, 7530-7546. https://doi.org/10.1002/2016JC011757

Meredith, M. P., Gordon, A. L., Naveira Garabato, A. C., Abrahamsen, E. P., Huber, B. A., Jullion, L., \& Venables, H. J. (2011). Synchronous intensification and warming of Antarctic bottom water outflow from the Weddell Gyre. Geophysical Research Letters, 38, L03603. https://doi.org/10.1029/2010GL046265

Mosby, H. (1934). The waters of the Atlantic Antarctic Ocean, in Scientific Results of the Norwegian Antarctic Expedition, $1927-1928$.

Naveira Garabato, A. C., Dotto, T. S., Hooley, J., Bacon, S., Tsamados, M., Ridout, A., et al. (2019). Phased response of the subpolar Southern Ocean to changes in circumpolar winds. Geophysical Research Letters, 46, 6024-6033. https://doi.org/10.1029/2019GL082850

Nicholls, K. W., østerhus, S., Makinson, K., Gammelsrød, T., \& Fahrbach, E. (2009). Ice-ocean processes over the continental shelf of the southern Weddell Sea, Antarctica: A review. Reviews of Geophysics, 47, RG3003. https://doi.org/10.1029/2007RG000250

Nøst, O. A., Biuw, M., Tverberg, V., Lydersen, C., Hattermann, T., Zhou, Q., et al. (2011). Eddy overturning of the Antarctic slope front controls glacial melting in the Eastern Weddell Sea. Journal of Geophysical Research, 116, C11014. https://doi.org/10.1029/2011JC006965

Núñez Riboni, I., \& Fahrbach, E. (2009). Seasonal variability of the Antarctic coastal current and its driving mechanisms in the Weddell Sea. Deep Sea Research Part I: Oceanographic Research Papers, 56(11), 1927-1941. https://doi.org/10.1016/j.dsr.2009.06.005

Orsi, A. H., Johnson, G. C., \& Bullister, J. L. (1999). Circulation, mixing, and production of Antarctic bottom water. Progress in Oceanography, 43(1), 55-109. https://doi.org/10.1016/S0079-6611(99)00004-X

Park, Y.-H., Charriaud, E., Craneguy, P., \& Kartavtseff, A. (2001). Fronts, transport, and Weddell Gyre at $30^{\circ}$ E between Africa and Antarctica. Journal of Geophysical Research, 106(C2), 2857-2879. https://doi.org/10.1029/2000JC900087

Reeve, K. A., Boebel, O., Kanzow, T., Strass, V., Rohardt, G., \& Fahrbach, E. (2016). A gridded data set of upper-ocean hydrographic properties in the Weddell Gyre obtained by objective mapping of Argo float measurements. Earth System Science Data, 8(1), 15-40. https://doi.org/10.5194/essd-8-15-2016

Ryan, S., Hattermann, T., Darelius, E., \& Schröder, M. (2017). Seasonal cycle of hydrography on the eastern shelf of the Filchner Trough, Weddell Sea, Antarctica. Journal of Geophysical Research: Oceans, 122, 6437-6453. https://doi.org/10.1002/2017JC012916

Ryan, S., Schröder, M., Huhn, O., \& Timmermann, R. (2016). On the warm inflow at the eastern boundary of the Weddell gyre. Deep Sea Research Part I: Oceanographic Research Papers, 107, 70-81. https://doi.org/10.1016/j.dsr.2015.11.002

Spence, P., Holmes, R. M., Hogg, A. M., Griffies, S. M., Stewart, K. D., \& England, M. H. (2017). Localized rapid warming of West Antarctic subsurface waters by remote winds. Nature Climate Change, 7, 595. https://doi.org/10.1038/nclimate3335

Stewart, A. L., Klocker, A., \& Menemenlis, D. (2019). Acceleration and overturning of the Antarctic slope current by winds, eddies, and tides. Journal of Physical Oceanography, 49(8), 2043-2074. https://doi.org/10.1175/JPO-D-18-0221.1

Stewart, A. L., \& Thompson, A. F. (2016). Eddy generation and jet formation via dense water outflows across the Antarctic continental slope. Journal of Physical Oceanography, 46(12), 3729-3750. https://doi.org/10.1175/jpo-d-16-0145.1

$\mathrm{Su}$, Z., Stewart, A. L., \& Thompson, A. F. (2014). An idealized model of Weddell gyre export variability. Journal of Physical Oceanography, 44(6), 1671-1688. https://doi.org/10.1175/JPO-D-13-0263.1 
Thompson, A. F., \& Heywood, K. J. (2008). Frontal structure and transport in the northwestern Weddell Sea. Deep Sea Research Part I: Oceanographic Research Papers, 55(10), 1229-1251. https://doi.org/10.1016/j.dsr.2008.06.001

Thompson, A. F., Stewart, A. L., Spence, P., \& Heywood, K. J. (2018). The Antarctic slope current in a changing climate. Reviews of Geophysics, 56, 741-770. https://doi.org/10.1029/2018RG000624

Timmermann, R., Wang, Q., \& Hellmer, H. (2012). Ice-shelf basal melting in a global finite-element sea-ice/ice-shelf/ocean model. Annals of Glaciology, 53(60), 303-314. https://doi.org/10.3189/2012AoG60A156

Treasure, A. M., Roquet, F., Ansorge, I. J., Bester, M. N., Boehme, L., Bornemann, H., et al. (2017). Marine mammals exploring the oceans pole to pole: A review of the MEOP consortium. Oceanography, 30, 132-138. https://doi.org/10.5670/oceanog.2017.234

Tschudi, W. N. M. J. S. S. C. F., \& Maslanik, J. (2019). Polar pathfinder daily $25 \mathrm{~km}$ ease-grid sea ice motion vectors, version 4. Boulder, Colorado, USA. National Snow and Ice Data Center Distributed Active Archive Center. https://doi.org/10.5067/INAWUWO7QH7B Van Caspel, M. (2016). The importance of the western Weddell Sea to Weddell Sea deep water formation.

Wang, Q., Danilov, S., Fahrbach, E., Schröter, J., \& Jung, T. (2012). On the impact of wind forcing on the seasonal variability of Weddell Sea bottom water transport. Geophysical Research Letters, 39, L06603. https://doi.org/10.1029/2012GL051198

Zhou, Q., Hattermann, T., Nøst, O. A., Biuw, M., Kovacs, K. M., \& Lydersen, C. (2014). Wind-driven spreading of fresh surface water beneath ice shelves in the Eastern Weddell Sea. Journal of Geophysical Research: Oceans, 119, 3818-3833. https://doi.org/10.1002/ 2013JC009556 